\title{
INCENTIVE MECHANISM FOR PERFORMANCE-BASED PAYMENT OF INFRASTRUCTURE PPP PROJECTS: COUPLING OF REPUTATION AND RATCHET EFFECTS
}

\author{
Huimin $\mathrm{LI}^{1,2}$, Limin $\mathrm{SU}^{3,}$, Jian $\mathrm{ZUO}^{2}$, Xianbo $\mathrm{ZHAO}^{4}$, Ruidong $\mathrm{CHANG}^{2}$, Fuqiang WANG ${ }^{1}$ \\ ${ }^{1}$ Department of Construction Engineering and Management, North China University of Water Resources and \\ Electric Power, Zhengzhou, PR China \\ ${ }^{2}$ School of Architecture and Built Environment, Centre for Asian and Middle Eastern Architecture, \\ University of Adelaide, Adelaide, Australia \\ ${ }^{3}$ School of Mathematics and Statistics, North China University of Water Resources and Electric Power, \\ Zhengzhou, PR China \\ ${ }^{4}$ School of Engineering and Technology, Central Queensland University, Sydney, NSW, Australia
}

Received 16 December 2020; accepted 06 October 2021; first published online 06 January 2022

\begin{abstract}
The performance-based payment PPP model has been widely used in the infrastructure projects. However, the ratchet effect derived from performance-based reputation incentives has been largely overlooked. To overcome this shortcoming, ratchet effect is considered in the performance-based payment incentive process. A multi-period dynamic incentive mechanism is developed by coupling the reputation and ratchet effect. The main results show that: (1) Under the coupling of reputation and ratchet effects, the optimal incentive coefficient in the last performance assessment period is always greater than that of the first period. The bargaining power can replace part of the incentive effect; (2) Due to the ratchet effect, if the government improve performance targets through performance adjustment coefficients, it needs to increase incentives to overcome the decreasing effort of the private sector; (3) When the bargaining power and punishment coefficient are small, the reputation incentive is replacing the explicit incentive. The increasing incentive coefficient would make the ratchet effect dominant the reputation effect; (4) To prevent the incentive incompatibility derived from the ratchet effect, the government should increase the incentive while increasing the punishment to achieve the "penalties and rewards". This study provides theoretical and methodological guidance to design incentive contracts for infrastructure PPP projects.
\end{abstract}

Keywords: infrastructure project, public-private partnership, incentive mechanism, reputation effects, ratchet effects.

\section{Introduction}

Public-private partnership (PPP) is a long-term cooperative concession agreement between the public and the private sector, which has been extensively used in the infrastructure projects, such as the transportation infrastructure (Geddes \& Reeves, 2017), sports facilities (van den Hurk \& Verhoest, 2017), water project (Elwakil \& Hegab, 2020), and waste-to-energy plants (Liu et al., 2018; Arbulu et al., 2017). PPP model can effectively broaden the sources of funds for infrastructure and public service projects whereas reducing the financial pressure on the public sector (Li et al., 2020a). It promotes the diversification of investors, assists in expanding the investment field of the private sector, and stimulates the vitality of the market
(Hueskes et al., 2017; Cheng et al., 2016). The PPP model gives full play to the functional advantages of the public sector and private sector, and promotes the continuous improvement of the supply quality and service efficiency of public infrastructure by introducing the private sector and advanced technical management experience.

In the last decades, PPP has advanced from a demandbased to a performance-based payment that focuses greater on improving the effectiveness of undertaking improvement and operations by means of introducing superior techniques, innovation, and administration from the private sector (Shang \& Aziz, 2020). This trend is named availability payments (i.e., a typical type of payment used in performance-based PPPs). In a performance-based

${ }^{*}$ Corresponding author. E-mail: suliminlove2010@163.com 
PPP agreement, the private sector would receive periodic payments from the public sector in the concession term. The payments are determined based on the quality of performance, and deductions are made if the performance falls below the required standard (Shang \& Aziz, 2020). There are two kinds of performance-based payment for infrastructure PPP. The first one is a single unitary charge, which is made for construction and operating costs. The second one is the separate charges for the availability and performance, which compensate for construction investment from the private sector and the operating cost covered by performance payment (Shi et al., 2020).

The performance-based payment mechanism not only defines how the private sector would be compensated but also has incentive effects (Shi et al., 2020). Zhang (2005) argued that a key principle in PPP is the link between performance and incentive payments based on successfully providing services to the government. The performancebased payment mechanism includes both positive and negative incentive effects (Shi et al., 2020). Li et al. (2020) proposed a real option-based nonlinear integer programming approach to solve the financial incentive allocation problem, and Real option theory is used to leverage to determine the optimal timing and the corresponding option value of providing financial incentives. For the performance-based payment mechanism, there is a wellestablished performance standard, and positive incentive effects will be obtained when the performance level is higher than the performance standard. Conversely, negative incentive effects will be got if the performance level is lower than the performance standard. In an impertinent agreement, the private sector will make unproductive efforts to reduce the construction and operational cost while sacrificing the quality of services, which cannot be wellspecified (Hart, 2003). Lack of public sector supervision and incentive will lead to the service quality and efficiency of PPP projects to fail to meet social needs (Zhang et al., 2018; Li et al., 2020b).

The essence of the PPP project is the principal-agent relationship between the public sector and the private sector. Conflicts of interest between the public and the private sectors occur due to misaligned goals among the partners ( $\mathrm{Li}$ et al., 2020b). The public tries to maximize the social and public interests, whereas the private sector tries to maximize their economic benefit, probably enticing investors to take opportunistic behavior that harms the project in their pursuit of self-interests, especially during the operational period (Han et al., 2019; Liu et al., 2016). Therefore, it is of vital importance to understand and determine the ways to motivate private sectors, to govern the development of PPP project participants, and to prevent the occurrence of opportunistic behaviors of the private sector (Mohamed et al., 2011), which displays as a behavior of protect and increase their own interests as much as possible and even tend to benefits at the expense of others in economic activities. Simultaneously, Moral hazard triggered by information asymmetry will happen. That is, under the condition of information asymmetric, the party with information advantage should have the ability to fulfill its obligations, but for the sake of maximizing its own utility, it may make breach of contract in favor of itself but not the other party, and even bring the risk of unexpected loss to the party with information disadvantage through hide its default behavior. And another behavior related to Moral hazard is adverse selection. One of its definitions in economics is that the inferior quality products, which are caused by both of the information asymmetric between two parties and the decrease of market price, drive out high-quality products, and then the average quality of the products decreases in the market.

To governing these behaviors stated above, the compensation scheme for the private sector is often followed by a performance target set by the government, which acted as an evaluation criterion of performance. In order to earn more profit in the future, the private sector will make a reasonable effort to improve the PPP project performance to maintain a good reputation, that is, reputation effect (Li et al., 2020b). However, the scheme often generates side-effects, that is, the ratchet effect (Choi \& Thum, 2003). In particular, under the non-competitive system, if the current performance evaluation standard is set according to the past performance, the incentive mechanism will be weakened. The high historical performance will lead to the high current standard, and the circulation scrolls up by such analogy in the future (Luo et al., 2016), and the private sector, as an agent, would reduce effort or lower the real performance, to weaken the pressure produced by the growing performance target. This manipulative behavior is defined as deflated performance manipulation (Luo et al., 2016). Therefore, to motivate the private sector to improve the infrastructure PPP project performance with a performance-based reputation mechanism, the ratchet effect would likely materialise. Ratchet and reputation effects interact within a contract, and they ultimately affect the behavior of private sector as the contract parameters change. In this study, we defined the interaction effect as a coupling effect. Coupling refers to the phenomenon of two or more systems that affect one another through various interactions (Fu et al., 2020), and originates from the field of physics (Li et al., 2012). This highlights a significant research gap that how the two opposite effects of ratchet and reputation impact on the behavior of the private sector, and how to design optimal incentive mechanism to handle the two effects.

To investigate the coupling effect of reputation and ratchet effects, we construct a multi-period dynamic incentive mechanism model in a general scheme, due to both the ratchet effect and the reputation effect referring to long-term incentives in the concession period. The objectives of this study is to explore how the private sector balance its effort involvement and deflated performance manipulation, and how to help the government to improve the incentive scheme and supervision. The main contributions of this study are as follows: (1) A multi-period 
dynamic incentive mechanism model under the coupling of reputation and ratchet effects is established to achieve the balance of interests between government and private sector; (2) The influence law that the optimal incentive level from government in each performance assessment period varies with the different influencing factors is revealed, which provides provide the academic reference for government; (3) The set of different performance goals for government is investigated according to the optimal effort level and deflated performance manipulation degree of private sectors; (4) Theoretical and methodological guidance are given to design incentive contracts of infrastructure PPP projects for government, and to encourage private sector to work harder to promote social benefits effectively.

The remainder of this paper is organized as follows. Section 1 is the literature review of the incentive mechanism in PPP projects and reputation effect and ratchet effect in principal-agent theory. Section 2 describes the research methodology in detail and constructs the incentive mechanism of PPP projects with reputation and ratchet effects. Section 3 presents the result analysis for the model. The discussion with numerical simulation is in Section 4. The last section provides conclusions.

\section{Literature reviews}

\subsection{Incentive mechanism for PPP projects}

The public and private sector in infrastructure PPP projects are regarded as the principal-agent relationship. In general, the phenomenon of information asymmetry between the public and private sectors is particularly prominent. The public sector, as the principal, is at the information disadvantage, while the private sector, as the agent, has complete information. The asymmetry of information requires an efficient incentive mechanism to be designed on the premise of the unification of the interests of principal and agent (Domingues \& Zlatkovic, 2015). This enables promotion of the investment enthusiasm and effort level of the private sector under an asymmetric information circumstance through appropriate incentive mechanisms (Ke et al., 2009; Yi, 2016) and suitable supervision strength (Guasch et al., 2006).

The incentive mechanism design of PPP projects means that the public sector motivates the private sector through contracts to maximize social benefits while enabling the private sector to achieve its expected returns. The objective is to achieve reasonable risk-sharing, inhibit opportunistic behaviors of the private sector, and improve the performance level of the project. The previous research about incentive mechanism focuses on opportunistic behavior, supervision management, and compensation mechanism. The supervision of the government could effectively restrain the opportunistic behaviors of the private sector (Koo et al., 2013), and effective supervision mechanism could promote the success of PPP projects (Mohamed, 2015). Subsequently, Greco (2015) employed the principal-agent theory to construct an incentive and supervision model from the perspective of government, and explored how the government chooses incentive ways and supervision levels for the private sector. Liu et al. (2016) introduced the speculation model based on the principal-agent theory, proving that the incentive intensity and interest distribution ratio are positively correlated with the level of social productivity, and can significantly weaken the opportunistic behaviors of the private sector. Peran (2008) found that the subsidy behavior of the government affected the performance level of PPP projects in the operation period.

The incentive mechanism for performance-based payment refers to design an incentive mechanism for PPP projects based on project performance evaluation results. Some scholars gives their attentions on it. Fearnley et al. (2004) studied the urban rail transit project in Norway and calculated the optimal government compensation incentive based on performance. Deng et al. (2009) established a dynamic adjustment mechanism for performance incentive indexes of PPP projects in terms of government, private sector, and public satisfaction, and carried out dynamic price adjustment and subsidy for PPP projects. Xu and Song (2010) analyzed the relevant factors that affect the optimal effort level of the private sector and the government rewards and punishments based on the constructed performance incentive contract. Zhang and Qiao (2018) developed the PPP project performance incentive model and discussed the influencing factors of the government's comprehensive utility and the private sector's economic utility.

Most of existing studies focused on protecting the fundamental interests of the government, private sector, and public. However, two problems exist. The first one is that the current studies cannot comprehensively analyze the dynamic adjustment for a contract in the concession period of the infrastructure PPP project. The second one is that the ratchet effect of the performance-based incentive model is largely overlooked.

\subsection{Reputation effect and ratchet effect}

\subsubsection{Reputation effect}

In the 1980s, researchers introduced dynamic game theory into the framework of the principal-agent theory. With the development of incentive theory, dynamic game theory was used to explore the reputation problem of the principal-agent relationship. The most representative ones are the standard model of Kreps, Milgrom, Roberts and Wilson (KMRW) (Kreps et al., 1982) and the agent market reputation model of Holmstrom (Holmström, 1999), both of them indicated that reputation is not immutable. It has long-term uncertainty and complexity, and it is a mechanism of interaction. Reputation can substitute for material in the form of implicit incentives for agents throughout multiple games (Lai et al., 2015; Jaramillo \& Srikant, 2010). Fama (1980) introduced reputation into 
an incentive mechanism. They proposed that an implicit incentive can be an incomplete substitute for an explicit incentive. Even if there is no explicit incentive, agents work hard to improve their reputation in the agent market, so as to improve their future competitiveness (Guetler \& Guetler, 2014; Hu et al., 2018; Tadelis, 2016). There have also many research on the reputation effect in the PPP field. Li et al. (2020b) constructed a two-period dynamic incentive model for urban water environment treatment PPP projects by introducing a reputation mechanism to solve the moral hazard and the opportunistic behaviors of the private sector, and explored the effective conditions for exerting the reputation incentive effects. Zhang et al. (2008) concluded partner's reputation and collaboration effects do have a significant positive relationship during the process of PPP, while trust relationship enhance the positive relationship between partner's reputation and collaboration effects. These studies have indicated that in a normal market credit environment, moral hazard and opportunistic behaviors can be avoided by establishing an incentive mechanism that considers reputation and restrains agents' long-term behaviors.

\subsubsection{Ratchet effect}

The ratchet effect is often present in the dynamic incentive mechanism, a common problem of dynamic incentive in principal-agent theory, and verified by a series of empirical evidence (Villegas et al., 2005; Freixas et al., 1985). In the principal-agent relationship, the better the performance of the agent is, the higher the requirement of the principal on the future performance of the agent is (Beyer et al., 2014). This phenomenon is known as the ratchet effect (Laffont \& Tirole, 1988). In order to reduce current real performance, the agent often balances effort reduction and deflated performance manipulation (Luo et al., 2016). The deflated performance manipulation behavior can help the private sector use the unreported surplus performance to smooth performance in the next period, so as to guarantee seemly performance growth. Rablen (2010) employed goal-setting theory to explain why agents tend to take the risk to attain a high target. It was reported that agent would reduce their real performance in various ways, for example, reducing investments (Eldenburg et al., 2011), allowing for price discounts (Roychowdhury, 2006), because deflated performance manipulation is concealed and is challenging to be detected (Bouwens \& Kroos, 2011). Charness et al. (2011) showed that the ratchet effect mostly existed in the labor market without competition, and proposed to increase competition to improve the ratchet effect. When the agent realizes that its own efforts will improve the standard, it will choose to reduce its efforts (Bouwens \& Kroos, 2011). However, there is no research about the ratchet effect in the construction management and PPP field. And research from other fields can provide lessons on what to do for us.

In a performance-based incentive contract of infrastructure PPP project, both the reputation effect and ratchet effect influence the behavior of the private sector. However, the mechanism of influence is still unclear. Furthermore, the coupling effect of reputation effect and ratchet effect is still to be revealed for us. How to establish an effective and resilient adjustment mechanism for the performance-based payment PPP projects to ensure the flexibility of the contract in the franchise period is the objective of this study.

\section{Methodology}

This section will give the methodology for establishing a multi-period dynamic incentive mechanism model under the coupling of reputation and ratchet effects. The framework of research is shown in Figure 1.

\subsection{Description for dynamic incentive model incorporating the reputation and ratchet effects}

The franchise period of infrastructure PPP projects is divided into different stages according to the performance assessment cycle. The government will pay the operation and maintenance expenses and profit to the private sector according to its performance appraisal score, and the private sector will gain the economic benefits through the operation and maintenance of the project. In the whole franchise

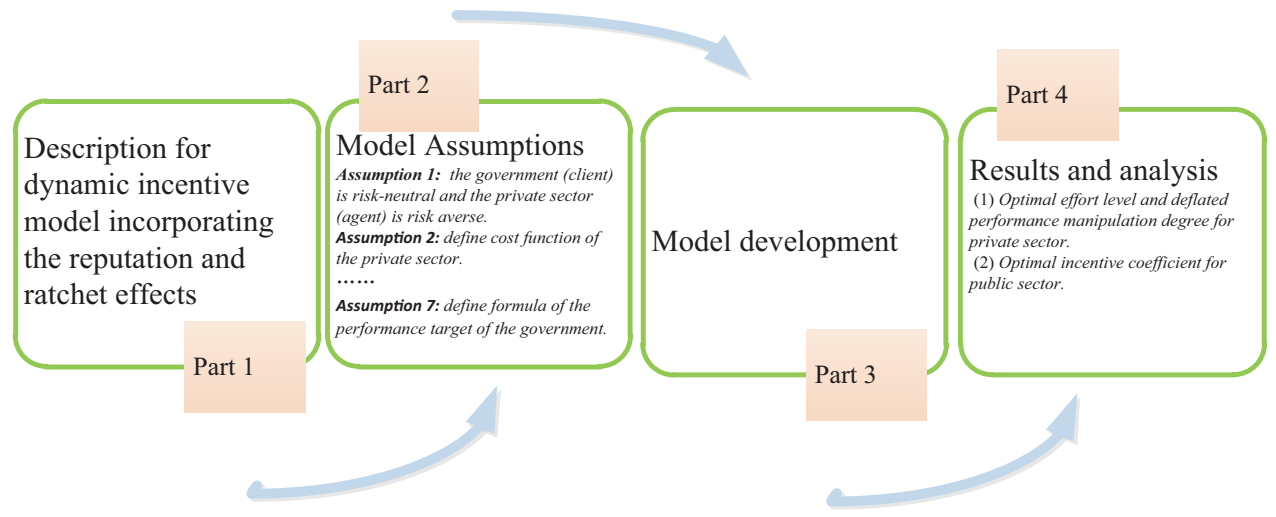

Figure 1. The research framework of methodology 
period, the game sequence between the government and the private sector is as follows: (1) the government will determine the incentive contract at the initial stage of performance appraisal; (2) the private sector will select the effort level according to the contract and obtain the performance output of the first performance cycle; (3) the government will adjust the incentive contract of the second performance cycle according to the performance output of the private sector in the first performance cycle; and (4) the private sector will select the effort level according to the contract formulated by the government in the second performance cycle. The performance output in the second performance cycle is obtained. The performance assessment goes in cycles until the end of the franchise period.

The model of the ratchet effect proves that if the client uses the information obtained from the past performance of the agent, the work enthusiasm of the agent will be reduced relatively (Gibbons, 1992). In the process of a long-term incentive of infrastructure PPP project, the government will take the previous performance of the private sector as the assessment standard. The previous performance of the private sector is related to its level of effort, when the input is fixed. Namely, the efforts of the private sector may be directly proportional to its performance assessment results, and the "standard" would be raised up. This tendency for performance standards to rising with performance is known as the ratchet effect (named as whipping the fast and hard working) (Gibbons, 1992). Therefore, when the private sector predicts that their efforts would raise the "standards", their enthusiasm for their efforts will reduce. The action of reducing efforts and initiative of preventing ratchet effect is called performance manipulation. And the difference between the performance level and the actual performance level in this situation is called performance manipulation level.

Therefore, the role of the "ratchet effect" in the longterm incentive process of infrastructure PPP projects is considered further. The multi-period dynamic incentive mechanism model with the coupling of reputation and ratchet effects is constructed to explore the influence of the two effects on the incentive mechanism designed by the government and the behavior of the private sector.

The input and effort level of the private sector in the $n$th performance appraisal cycle are abbreviated as $\theta_{n}$ and $e_{n}$, respectively. The performance appraisal score of the private sector in is denoted as $x_{n}=\theta_{n} e_{n}$. The standard performance score set by the government in the $n$th performance appraisal cycle is denoted as $x_{n}^{0}=\theta_{n} e_{n}^{0}$, wherein $e_{n}^{0}$ indicates the basic effort level of the private sector in the $n$th performance cycle. It is assumed that $A_{n}$ is the payment given by the government to the private sector in the $n$ performance cycle, and the incentive contract given by the government is linear as follows (Gibbons, 1992).

$$
A_{n}=A\left(\pi_{n}\right)=a_{n}+\beta_{n}\left(\pi_{n}-\pi_{0}\right),
$$

where: $a_{n}$ indicates to the fixed payment given by the government to the private sector; $\beta_{n}\left(\pi_{n}-\pi_{0}\right)$ indicates the performance payment given by the government to the private sector; $\beta_{n} \in[0,1]$ indicates the incentive coefficient set by the government according to the performance output of the project; $\pi_{n}$ and $\pi_{0}$ indicate the performance output of the private sector and the performance output standard set by the government, respectively.

If the value of incentive coefficient is too large or too small, it is not conducive to the smooth implementation of the project. Specifically, although the private sector can be encouraged to do its best to improve performance to some extent when the incentive coefficient is too large, the payment from the government will also be increased. On the contrary, if the incentive coefficient value is too small, the enthusiasm of the private sector will not be stimulated the efforts to increase performance level. Therefore, the design of the incentive mechanism is to take both the government and private sectors into account and set an appropriate incentive coefficient, so as to motivate the private sector side to improve the performance actively to achieve better social benefits, at the same time, maximize the income of the private sector.

Before giving model assumptions, a symbol interpretation are as shown in Table 1.

Table 1. The performance manipulation degree and the influencing factors

\begin{tabular}{|c|c|}
\hline Symbol & Interpretation of symbols \\
\hline$a_{n}$ & indicates to the fixed payment given by the government to the private sector \\
\hline$\pi_{n}, \pi_{0}$ & $\begin{array}{l}\pi_{n} \text { and } \pi_{0} \text { indicate the performance output of the private sector and the performance output standard set by the } \\
\text { government, respectively }\end{array}$ \\
\hline$\underline{\pi}_{0}$ & $\underline{\pi}_{0}$ indicates the performance output standard set by the government \\
\hline$\tilde{\pi}_{n}$ & $\begin{array}{l}\tilde{\pi}_{n} \text { indicates the performance output of the private sector observed by the government in the } n \text {th performance } \\
\text { assessment cycle }\end{array}$ \\
\hline$\beta_{n} \in[0,1]$ & indicates the incentive coefficient set by the government according to the performance output of the project \\
\hline$\beta_{n}\left(\pi_{n}-\pi_{0}\right)$ & indicates the performance payment given by the government to the private sector \\
\hline$\theta_{n}, e_{n}$ & $\theta_{n}$ and $e_{n}$ indicate the input and effort level of the private sector, respectively \\
\hline$\mu_{n}$ & $\begin{array}{l}\mu_{n} \sim N\left(0, \sigma^{2}\right) \text {, where } \sigma^{2} \text { is directly proportional to the information asymmetry as well as the influence of exogenous } \\
\text { factor to the performance output }\end{array}$ \\
\hline$k$ & $k$ indicates the output coefficient \\
\hline
\end{tabular}


End of Table 1

\begin{tabular}{|c|l|}
\hline Symbol & \multicolumn{1}{|c|}{ Interpretation of symbols } \\
\hline$x_{n}$ & $x_{n}$ indicates the performance appraisal score of the private sector in the $n$th performance cycle \\
\hline$\rho$ & $\rho(\rho>0)$ indicates its absolute risk aversion coefficient \\
\hline$c$ & $c$ indicates the cost coefficient \\
\hline$\eta$ & $\begin{array}{l}\eta \sim N\left(0, \tau \sigma^{2}\right) \text { indicates the operation ability of the private sector in the PPP project (assuming that it is not related } \\
\text { with time })\end{array}$ \\
\hline$r$ & $r>0$ indicates the coefficient of supervision cost \\
\hline$h_{n}$ & $0<h_{n}<1$ indicates the supervision intensity of the government \\
\hline$l$ & $0<l<1$ indicates the coefficient of target adjusting \\
\hline$\hat{e}_{n}$ & $\hat{e}_{n}$ indicates the expected level effort of government towards the private sector \\
\hline$s$ & $\begin{array}{l}s \geq 0 \text { indicates the bargaining power of the private sector, and the bargaining power of the private sector is directly } \\
\text { proportional to the role of the reputation mechanism }\end{array}$ \\
\hline$\delta_{1}$ & $0<\delta_{1}<1$ indicates the discount rate while calculating inter-term income \\
\hline
\end{tabular}

\subsection{Model assumptions}

The performance output of the private sector in the $n$th performance assessment cycle of the PPP project is

$$
\pi_{n}=k x_{n}+\mu_{n}
$$

where: $x_{n}=\theta_{n} e_{n}$ indicates the performance appraisal score of the private sector in the $n$th performance cycle, where $\theta_{n}$ and $e_{n}$ indicate the input and effort level of the private sector, respectively; $k$ indicates the output coefficient; and $\mu_{n}$ indicates the exogenous random factor. In addition, $\mu_{n} \sim N\left(0, \sigma^{2}\right)$, where $\sigma^{2}$ is directly proportional to the information asymmetry as well as the influence of exogenous factor to the performance output.

The performance output $\pi_{n}$ is mainly measured by the performance appraisal score. When $x_{n} \geq x_{n}^{0}$, it can be indicated that the output exceeds the expected of the government. At this point, the government should give rewards to the private sector. On the contrary, if $x_{n}<x_{n}^{0}$, it indicates that the output of project operation does not reach the expected of the government, and the private sector should be punished. According to Equation (1), it can be known that the rewards and punishments of the private sector in the $n$th performance assessment cycle is $\beta_{n} k\left(x_{n}-x_{n}^{0}\right)$. The incentive coefficient $\beta_{n}$ is directly proportional to the rewards and punishments of the private sector from the government in the $n$th performance assessment cycle.

Hart and Holmström (1986) argued that the government should be risk-neutral in a dynamic setting. Accordingly, we put forward the following.

Assumption 1: We assume that the government (client) is risk-neutral and the private sector (agent) is riskaverse in the infrastructure PPP project. The utility function of the private sector is absolute risk aversion, and $\rho(\rho>0)$ indicates its absolute risk aversion coefficient.

The incentive contract $A\left(\pi_{n}\right)$ between the government and the private sector in the $n$th performance cycle of the infrastructure PPP project is (Gibbons, 1992):

$$
A_{n}=A\left(\pi_{n}\right)=a_{n}+\beta_{n}\left(\pi_{n}-\pi_{0}\right),
$$

where $a_{n}$ indicates the fixed payment given by the government to the private sector in the $n$th performance assessment cycle. In other words, if the private sector carries out basic maintenance during the franchise period, it can get a part of fixed income. In addition, $\beta_{n} \in[0,1]$ indicates the incentive coefficient set by the government, and $\underline{\pi}_{0}$ indicates the performance output standard set by the government.

There is a cost $C\left(e_{n}, \theta_{n}\right)$ to extent an effort $e_{n}$ and input $\theta_{n}$, and the cost is concave. For giving more detailed analysis, we assume the following assumption.

Assumption 2: We assume that $e_{n}$ and $\theta_{n}$ are the effort level and input of the private sector in the $n$th performance assessment cycle, respectively. The cost function of the private sector (Gill \& Stone, 2010) is

$$
C\left(e_{n}, \theta_{n}\right)=c\left(e_{n}^{2}+\theta_{n}^{2}\right) / 2,
$$

where $c$ indicates the cost coefficient.

Assumption 3: We assume that the private sector is risk-averse, and its risk cost in the $n$th performance assessment cycle is

$$
R C=\rho \sigma_{n}^{2} / 2 .
$$

In actual infrastructure PPP projects, the performance output is not only related to the effort level and the input of the private sector, but also related to the operation ability of the private sector. Therefore, the operation ability of the private sector is further introduced on the basis of performance output function in Equation (2).

Assumption 4: We assume that the performance output of the private sector in the $n$th performance assessment cycle of the infrastructure PPP project is

$$
\pi_{n}=k x_{n}+\eta+\mu_{n},
$$

where: $x_{n}$ indicates the performance appraisal score of the private sector in the $n$ performance assessment cycle; $k$ indicates the coefficient of benefit output; $\eta \sim N\left(0, \tau \sigma^{2}\right)$ indicates the operation ability of the private sector in the PPP project (assuming that it is not related with time); and $\mu_{n} \sim N\left(0,(1-\tau) \sigma^{2}\right)$ indicates an exogenous random variable. It is assumed that the random variables 
$\mu_{n}(n=1,2, \cdots, N)$ are independent of each other; namely, $\operatorname{cov}\left(\mu_{n}, \mu_{m}\right)=0, m \neq n$ and $\tau=\frac{\operatorname{var}(\eta)}{\operatorname{var}(\eta)+\operatorname{var}\left(\mu_{n}\right)}$. Thus, $\operatorname{var}\left(\pi_{n}\right)=\sigma^{2}$, in which $\tau \in[0,1]$ indicates the ratio between the variance of the operational capability $\eta$ and the output function $\pi_{n}$; and $\operatorname{var}(\eta)$ is directly proportional to $\tau$.

Assumption 5: We assume that the private sector manipulates performance in the performance appraisal process, and the degree of performance manipulation in the $n$th performance assessment cycle is

$$
\Delta \pi_{n}=\pi_{n}-\tilde{\pi}_{n}=k x_{n}+\eta+\mu_{n}-\tilde{\pi}_{n},
$$

where $\tilde{\pi}_{n}$ indicates the performance output of the private sector observed by the government in the $n$th performance assessment cycle. This study assumes that the purpose of the private sector to manipulate performance is to hope that the performance output observed by the government is lower than its actual performance output, namely $\Delta \pi_{n} \geq 0$.

In order to restrain the performance manipulation of the private sector, the government will supervise the performance manipulation behavior. Once the performance manipulation of the private sector is detected, the government will punish it. It is assumed that the penalty function is $C_{d}=\frac{d}{2} \Delta \pi_{n}^{2}$, wherein $d>0$ indicates the penalty coefficient; the penalty function $C_{d}$ is a concave function, and $C_{d}{ }^{\prime}>0, C_{d}{ }^{\prime \prime}>0$.

Assumption 6: We assume that the cost of government supervision in the $n$th performance assessment cycle of infrastructure PPP projects is

$$
C\left(h_{n}\right)=r h_{n}^{2} / 2,
$$

where: $r>0$ indicates the coefficient of supervision cost; and $0<h_{n}<1$ indicates the supervision intensity of the government.

According to adaptive expectation theory (Luo et al., 2016), the government adjusts the performance target in the next performance assessment cycle according to the deviation between the target performance and the actual performance in the current performance assessment cycle.

Assumption 7: We assume that the performance target of the government in the $n+1$ th performance assessment cycle of the infrastructure PPP project is:

$$
\underline{\pi}_{n+1}=\underline{\pi}_{n}+l\left(\pi_{n}-\underline{\pi}_{n}\right)=l \pi_{n}+(1-l) \underline{\pi}_{n},
$$

where $0<l<1$ indicates the coefficient of target adjusting. In the first performance appraisal cycle, the government does not know the operation ability of the private sector, so it is assumed that $\pi_{1}=0$.

During the franchise period, although the government does not know the operational capability of the private sector, it can be estimated according to the historical performance. $\hat{e}_{n}=E\left(e_{n}\right)$ indicates the government's expected level of effort towards the private sector. In addition, the operation capability $\eta$ of the private sector and the exogenous factor $\mu_{n}$ cannot be separated, and it can be obtained that $\eta+\mu_{n}=\pi_{n}-k \theta_{n} \hat{e}_{n}$ according to Equation (6).

\subsection{Model development}

Based on the reputation effect, the private sector's effort and manipulation not only affect the current profit but also affect the future reputation. The manager's talent can be evaluated by the government based on the past performance. The government will evaluate the private sector's talent by the observation of historical performance while the private sector can affect such expectation by her effort and manipulation.

According to the rational expectations equation,

$$
E\left(\eta \mid \pi_{n}\right)=(1-\tau) E(\eta)+\tau\left(\pi_{n}-E\left(\pi_{n}\right)\right)=\tau\left(\pi_{n}-E\left(\pi_{n}\right)\right),
$$

that is to say, in the case of given performance output, the expected operational capability $\eta$ of the private sector from the government is the weighted average of its prior expectation $E(\eta)$ and observed value $\pi_{n}-E\left(\pi_{n}\right)$. According to the information observed, the government can adjust its judgment on the operational capacity of the private sector, wherein the prior uncertainty about capacity is directly proportional to the correction. This is because $\tau$ reflects the relevant information of $\eta$ included in $\pi_{n}$, and the value of $\tau$ is directly proportional to the amount of information included in $\pi_{n}$. In particular, if there is no prior uncertainty $(\operatorname{var}(\eta)=0)$ and $\tau=0$, the market will not be perfect; on the other hand, if the prior uncertainty is very large $(\operatorname{var}(\eta) \rightarrow \infty)$, or there is no exogenous uncertainty $\left(\operatorname{var}\left(\mu_{n}\right)=0\right)$ and $\tau=1$, the market will solely correct the judgment on $\eta$ according to the $\pi_{n}$ observed.

According to Assumption 7 and Equation (7), the expected operational capability of the private sector is:

$$
\begin{aligned}
& \gamma E\left(\eta \mid \pi_{n}\right)+(1-\gamma) E\left(\eta \mid \tilde{\pi}_{n}\right)= \\
& \gamma \tau\left(\pi_{n}-k \theta_{n} \hat{e}_{n}\right)+(1-\gamma) \tau\left(\tilde{\pi}_{n}-k \theta_{n} \hat{e}_{n}\right)= \\
& \tau\left[k \theta_{n} e_{n}+\eta+\mu_{n}-(1-\gamma) \Delta \pi_{n}-k \theta_{n} \hat{e}_{n}\right] .
\end{aligned}
$$

In the incentive contract, the government will adjust the fixed payment according to the reputation of the private sector, namely

$$
a_{n+1}=a_{n}+s\left[\gamma E\left(\eta \mid \pi_{n}\right)+(1-\gamma) E\left(\eta \mid \tilde{\pi}_{n}\right)\right],
$$

where $s \geq 0$ indicates the bargaining power of the private sector, and the bargaining power of the private sector is directly proportional to the role of the reputation mechanism.

According to the assumptions above, it can be known that the incentive contract model of the government in the $n+1$ th performance assessment cycle is:

$$
\begin{aligned}
& \tilde{A}_{n+1}\left(\pi_{n+1}\right)=a_{n+1}+\tilde{\beta}_{n+1}\left(\pi_{n+1}-\underline{\pi}_{n+1}\right)= \\
& a_{n}+s\left[\gamma E\left(\eta \mid \pi_{n}\right)+(1-\gamma) E\left(\eta \mid \tilde{\pi}_{n}\right)\right]+ \\
& \tilde{\beta}_{n+1}\left[\pi_{n+1}-l\left(\gamma \pi_{n}+(1-\gamma) \tilde{\pi}_{n}\right)\right] .
\end{aligned}
$$

In general, this study considers the design of the incentive mechanism model with two performance assessment cycles. When there are only two performance assessment cycles, the second cycle is the last cycle of the project. In the last cycle, the private sector would no longer consider the influence of reputation on its future income. 
To sum up, the utility function of the government and the income function of the private sector in the first performance assessment cycle are as follows, respectively:

$\tilde{\psi}_{G 1}=E\left(\pi_{1}-\gamma \tilde{A}\left(\pi_{1}\right)-(1-\gamma) \tilde{A}\left(\tilde{\pi}_{1}\right)+\frac{\gamma d}{2} \Delta \pi_{1}^{2}-\frac{r}{2} h_{1}^{2}\right)$

and

$\tilde{\Phi}_{P 1}=E\left(\gamma \tilde{A}\left(\pi_{1}\right)+(1-\gamma) \tilde{A}\left(\tilde{\pi}_{1}\right)-\frac{\gamma d}{2} \Delta \pi_{1}^{2}-\frac{c}{2}\left(\tilde{e}_{1}^{2}+\theta_{1}^{2}\right)-\frac{\rho}{2} \sigma_{1}^{2}\right)$.

In the second performance assessment cycle, the utility function of the government, and the income function of the private sector are as follows, respectively:

$\tilde{\psi}_{G 2}=E\left(\pi_{2}-\tilde{A}\left(\pi_{2}\right)-(1-\gamma) \tilde{A}\left(\tilde{\pi}_{2}\right)+\frac{\gamma d}{2} \Delta \pi_{2}^{2}-\frac{r}{2} h_{2}^{2}-(1-\gamma) \tilde{\beta}_{1} \Delta \pi_{1}\right)$

and

$\tilde{\Phi}_{P 2}=E\left(\gamma \tilde{A}\left(\pi_{2}\right)+(1-\gamma) \tilde{A}\left(\tilde{\pi}_{2}\right)-\frac{\gamma d}{2} \Delta \pi_{2}^{2}-\frac{c}{2}\left(\tilde{e}_{2}^{2}+\theta_{2}^{2}\right)-\frac{\rho}{2} \sigma_{1}^{2}-(1-\gamma) \tilde{\beta}_{1} \Delta \pi_{1}\right)$.

In summary, the incentive mechanism model of infrastructure PPP project with the coupling of reputation and ratchet effects is as follows:

$$
\max _{\tilde{\beta}_{1}, \tilde{\beta}_{2}}\left\{\tilde{\psi}_{G 1}+\delta_{1} \tilde{\psi}_{G 2}\right\} \text {, }
$$

where $0<\delta_{1}<1$ indicates the discount rate while calculating inter-term income. The model above should also meet two conditions as follows:

(1) Participation constraint: (IR) $\tilde{\Phi}_{P 1}+\delta_{1} \tilde{\Phi}_{P 2} \geq \Phi_{0}$;

(2) Incentive compatibility constraint:

$\left(\mathrm{IC}_{1}\right) \tilde{e}_{2}^{*}=\arg \max \tilde{\Phi}_{P 2}$,

$\left(\mathrm{IC}_{2}\right) \Delta \pi_{2}^{*}=\arg \max \tilde{\Phi}_{P 2}$,

$\left(\mathrm{IC}_{3}\right) \tilde{e}_{1}^{*}=\arg \max \left\{\tilde{\Phi}_{P 1}+\delta_{1} \tilde{\Phi}_{P 2}\right\}$,

$\left(\mathrm{IC}_{4}\right) \Delta \pi_{1}^{*}=\arg \max \left\{\tilde{\Phi}_{P 1}+\delta_{1} \tilde{\Phi}_{P 2}\right\}$.

The condition of participation constraint (IR) indicates that the expected utility of the private sector under the contract is greater than the maximum expected income (the benefit is called the retained utility) under other market opportunities. The incentive compatibility constraints $\mathrm{IC}_{1}$ and $\mathrm{IC}_{2}$ are the effort level $\tilde{e}_{2}$ and performance manipulation degree $\Delta \pi_{2}$ selected by the private sector for maximizing the expected performance in the second performance assessment cycle. The incentive compatibility constraints $\mathrm{IC}_{3}$ and $\mathrm{IC}_{4}$ are the effort level $\tilde{e}_{1}$ and performance manipulation degree $\Delta \pi_{1}$ selected by the private sector for maximizing the utility function of the two performance assessment cycles.

\section{Results and analysis}

\subsection{Optimal effort level and deflated performance manipulation degree for private sector}

(1) The optimal effort level and performance manipulation degree of the private sector in the second performance assessment cycle is as follows:

$$
\tilde{e}_{2}^{*}=\frac{\tilde{\beta}_{2} k \theta_{2}}{c}, \Delta \pi_{2}^{*}=0 \text {. }
$$

The proof processes are shown in Appendix 1.

It can be seen from Equation (10) that the reputation and ratchet effects lose their effect in the second performance assessment cycle. The optimal effort levels $\tilde{e}_{2}^{*}$ is positively correlated with $\tilde{\beta}_{2}, k$ and $\theta_{2}$ and negatively correlated with $c$. The performance manipulation degree of the private sector in the second performance assessment cycle is 0 .

The conclusions regarding the optimal effort level are as follows:

1) The optimal effort level $\tilde{e}_{2}^{*}$ is positively correlated with the incentive coefficient $\tilde{\beta}_{2}$. In the second performance assessment cycle, the reputation and ratchet effects lose their effect. The incentive coefficient is directly proportional to the degree of reward and punishment as well as the risk shared by the private sector. In this period, if the actual performance exceeds the target performance, the private sector will receive more rewards. Therefore, the private sector will actively improve their efforts to get more performance incentive income.

2) The optimal effort level $\tilde{e}_{2}^{*}$ is positively correlated with the input $\theta_{2}$ of the private sector. The input $\theta_{2}$ and effort level $\tilde{e}_{2}$ depict its performance appraisal score. When the input $\theta_{2}$ is fixed, $\tilde{e}_{2}$ is directly proportional to the performance appraisal score; that is to say, the input $\theta_{2}$ is directly proportional to the performance income as well as the effort.

3) The optimal effort level $\tilde{e}_{2}^{*}$ is positively correlated with the coefficient of social benefit output $k$. The coefficient $k$ is directly proportional to the social benefit in operation and maintenance process of the PPP project, and the incentive income of performance would be increase. Therefore, the enthusiasm for the efforts of the private sector can be improved naturally.

4) The optimal effort level $\tilde{e}_{2}^{*}$ is negatively correlated with the effort cost coefficient $c$. The value of $c$ is directly proportional to the risk undertaken by the private sector. Therefore, the private sector may select the effort level prudently to reduce the risk.

(2) The optimal effort level and performance manipulation degree of the private sector in the first performance assessment cycle is as follows:

$$
\begin{aligned}
& \tilde{e}_{1}^{*}=\frac{\tilde{\beta}_{1} k \theta_{1}+\delta_{1} k \theta_{1} s \tau-\delta_{1} \tilde{\beta}_{2} l k \theta_{1}}{c}, \\
& \Delta \pi_{1}^{*}=\frac{(1-\gamma)\left(\delta_{1} \tilde{\beta}_{2} l-\tilde{\beta}_{1}-\delta_{1} s \tau+\delta_{1} \tilde{\beta}_{1}\right)}{\gamma d} .
\end{aligned}
$$

The proof processes are shown in Appendix 1.

According to Equations (11) and (12), it can be known that the optimal effort level and performance manipulation degree of the private sector in the first performance assessment cycle are affected by multiple parameters. The correlations of the optimal effort level and performance manipulation degree to the parameters are analyzed as follows. 
According to Equation (11), it can be known that when $\tilde{\beta}_{1}+\delta_{1} s \tau-\delta_{1} \tilde{\beta}_{2} l \leq 0$, the optimal effort level of the private sector $\tilde{e}_{1}^{*}=0$. When $\tilde{\beta}_{1}+\delta_{1} s \tau-\delta_{1} \tilde{\beta}_{2} l>0$, the conclusions on the optimal effort level can be obtained as follows:

1) According to $\frac{\partial \tilde{e}_{1}^{*}}{\partial k}>0$, it can be known that the optimal effort level $\tilde{e}_{1}^{*}$ of the private sector in the first cycle is positively correlated with the coefficient of social benefit output $k$. Therefore, the private sector will improve its enthusiasm for efforts to increase the income, so as to improve reputation.

2) Because $\frac{\partial \tilde{e}_{1}^{*}}{\partial c}<0$, the optimal effort level $\tilde{e}_{1}^{*}$ of the private sector is negatively correlated with the cost coefficient $c$. The cost coefficient is directly proportional to its effort level as well as the risk undertaken by the private sector. Therefore, the private sector may select the effort degree prudently to reduce the risk.

3) According to $\frac{\partial \tilde{e}_{1}^{*}}{\partial \theta_{1}}>0$, it can be known that the input $\theta_{1}$ of the private sector is positively correlated with its optimal effort level $\tilde{e}_{1}^{*}$. The performance appraisal score is depicted together by $\theta_{1}$ and $\tilde{\mathrm{e}}_{1}^{*}$. When the input $\theta_{1}$ is fixed, the optimal effort level $\tilde{e}_{1}^{*}$ is directly proportional to the performance appraisal score.

4) According to $\frac{\partial \tilde{e}_{1}^{*}}{\partial \delta_{1}}>0$, it can be known that the optimal effort level $\tilde{e}_{1}^{*}$ is positively correlated with the discount rate $\delta_{1}$. The value of the discount rate $\delta_{1}$ will affect the expected future income of the private sector, and the $\theta_{1}$ is directly proportional to the discount of future income in the next cycle.

5) According to $\frac{\partial \tilde{e}_{1}^{*}}{\partial \tau}>0$, it can be known that the optimal effort level $\tilde{e}_{1}^{*}$ is positively correlated with the ratio $\tau$. The $\tau$ refers to the ratio between the variance of the operational capability and the performance output. When $\tau$ is at a high level, the amount of information on operational capability included in the performance output would be more, and exogenous uncertainty would be reduced. The exogenous uncertainty is reduced by the reputation effect. The higher reputation would enhance the fixed income of the private sector, and in turn, motivate the private sector to takes more effort for operation.

6) According to $\frac{\partial \tilde{e}_{1}^{*}}{\partial \tilde{\beta}_{1}}>0$, it can be known that the optimal effort level $\tilde{e}_{1}^{*}$ is positively correlated with the incentive coefficient $\tilde{\beta}_{1}$. The incentive coefficient is directly proportional to the degree of reward or punishment given by the government to the private sector as well as the risk undertaken by the private sector. Therefore, the private sector side will actively improve the effort level to improve the performance level under the reputation and ratchet effect.
7) According to $\frac{\partial \tilde{e}_{1}^{*}}{\partial s}>0$, it can be known that the optimal effort level $\tilde{e}_{1}^{*}$ is positively correlated with its bargaining power $s$. The bargaining power $s$ of the private sector is directly proportional to the reputation as well as the income from its fixed income part. Therefore, the private sector will be motivated to make more efforts to obtain more income and improve its reputation.

8) According to $\frac{\partial \tilde{e}_{1}^{*}}{\partial l}<0$, it can be known that the optimal effort level $\tilde{e}_{1}^{*}$ is negatively correlated with the performance adjustment coefficient $l$ set by the government. When the performance adjustment coefficient increases, it means that the performance target for the next stage increases. In order to reduce the magnitude of the growth of the performance target in the next phase, the private sector would reduce the effort level in the first phase in order to smooth the growth of the performance target. This is the effect of the ratchet effect.

It can be observed from Equation (12) that, when $\delta_{1} \tilde{\beta}_{2} l-\tilde{\beta}_{1}-\delta_{1} s \tau+\delta_{1} \tilde{\beta}_{1} \leq 0$, the performance manipulation degree of the private sector in the first cycle is $\Delta \pi_{1}^{*}=0$; when $\delta_{1} \tilde{\beta}_{2} l-\tilde{\beta}_{1}-\delta_{1} s \tau+\delta_{1} \tilde{\beta}_{1}>0$, the first derivative of each influencing factor of the optimal performance manipulation degree in Equation (12) is obtained, and the results are shown in Table 2. The decision-make of the performance manipulation degree is a complex process, which is influenced by the joint of multidimensional parameters. so we should discuss the relationship in a more multi-dimensional space.

Table 2. The performance manipulation degree and the influencing factors

\begin{tabular}{|c|l|l|}
\hline No. & First derivative & \multicolumn{1}{|c|}{ Description } \\
\hline 1 & $\partial \Delta \pi_{1}^{*} / \partial \tilde{\beta}_{1}<0$ & $\begin{array}{l}\text { The performance manipulation degree } \\
\Delta \pi_{1}^{*} \text { in the first cycle is negatively cor- } \\
\text { related with the incentive coefficient } \beta_{1}\end{array}$ \\
\hline 2 & $\partial \Delta \pi_{1}^{*} / \partial \gamma<0$ & $\begin{array}{l}\text { The probability } \gamma \text { of the government } \\
\text { finds the real level of performance } \\
\text { is negatively correlated with the } \\
\text { performance manipulation degree } \\
\text { of the private sector in the first cycle }\end{array}$ \\
\hline 3 & $\partial \Delta \pi_{1}^{*} / \partial l>0$ & $\begin{array}{l}\text { The performance manipulation degree } \\
\text { is positively correlated with the } \\
\text { performance adjustment coefficient } l \text { set } \\
\text { by the government }\end{array}$ \\
\hline 4 & $\partial \Delta \pi_{1}^{*} / \partial \delta_{1}>0$ & $\begin{array}{l}\text { The performance manipulation degree } \\
\Delta \pi_{1}^{*} \text { in the first cycle is positively } \\
\text { correlated with the discount rate } \delta_{1} \text { of } \\
\text { inter-period income }\end{array}$ \\
\hline 5 & $\partial \Delta \pi_{1}^{*} / \partial s<0$ & $\begin{array}{l}\text { The performance manipulation degree } \\
\Delta \pi_{1}^{*} \text { is negatively correlated with its } \\
\text { bargaining power } s \text { of the private sector }\end{array}$ \\
\hline 6 & $\partial \Delta \pi_{1}^{*} / \partial d<0$ & $\begin{array}{l}\text { The performance manipulation degree } \\
\Delta \pi_{1}^{*} \text { is negatively correlated with the } \\
\text { punishment coefficient } d\end{array}$ \\
\hline
\end{tabular}




\subsection{Optimal incentive coefficients}

The incentive coefficients $\tilde{\beta}_{1}$ and $\tilde{\beta}_{2}$ is as follows:

$\tilde{\beta}_{1}^{*}=\frac{l \theta_{1}^{2}-\theta_{2}^{2}-2 s \tau \delta_{1} l \theta_{1}^{2}}{2 \theta_{1}^{2} l}+\frac{A_{1}}{A_{2}}$,

$\tilde{\beta}_{2}^{*}=\frac{2 k^{4} \theta_{1}^{4} \gamma^{2} d^{2}-\gamma d B_{2} B_{3}}{B_{4} B_{2}-2 k^{2} \gamma d B_{2} B_{1}-2 k^{2} \theta_{1}^{2} \gamma d B_{4}+4 k^{4} \theta_{1}^{4} \gamma^{2} d^{2}}$,

where $B_{1}=\theta_{1}^{2} \delta_{1} l^{2}+\theta_{2}^{2}, B_{2}=\left(\delta_{1}-1-s \tau \delta_{1}\right)(1-\gamma)^{2} c\left(1-\delta_{1}\right)$,

$B_{3}=\theta_{2}^{2}+2 \theta_{1}^{2} \delta_{1} s \tau l-\theta_{1}^{2} l, B_{4}=\delta_{1}(1-\gamma)^{2} l^{2} c$, and

$A_{1}=4 k^{4} \theta_{1}^{4} \delta_{1} \gamma^{2} d^{2} B_{1}-2 k^{2} \theta_{1}^{4} \delta_{1} \gamma d B_{4}-2 k^{2} \delta_{1} \gamma d B_{3} B_{1} B_{2}+$

$\delta_{1} B_{4} B_{2} B_{3}, A_{2}=2 \theta_{1}^{2} \delta_{1}\left(B_{2}-2 k^{2} \theta_{1}^{2} \gamma d\right)\left(l B_{4}-1\right)+$

$2 \theta_{1}^{2} \delta_{1} B_{2}\left(1-2 k^{2} \theta_{2}^{2} l \gamma d-k^{2} \theta_{1}^{2} \delta_{1} l^{3} \gamma d\right)$.

The proof processes are appeared in Appendix 1.

From Equations (13) and (14), it can be seen that the optimal incentive coefficients $\tilde{\beta}_{1}^{*}$ and $\tilde{\beta}_{2}^{*}$ are related to the parameters $c, k, \theta_{1}, \theta_{2}, \tau, l, s, \delta_{1}, \gamma$ and $d$. The public sector dynamically adjusts the incentive coefficients to motivate the private sector to improve the performance to get better social benefits. Next, the correlation between the variation of each parameter and the optimal incentive coefficients $\tilde{\beta}_{1}^{*}$ and $\tilde{\beta}_{2}^{*}$ is analyzed in two steps by numerical simulation.

Step 1: According to $0<\tilde{\beta}_{1}^{*}<1$ and $0<\tilde{\beta}_{2}^{*}<1,151$ groups of data are randomly generated within the range of $[0,1]$ for each influencing parameter.

Step 2: According to the data distribution of each parameter, the influence relation of each parameters to the optimal incentive coefficients $\tilde{\beta}_{1}^{*}$ and $\tilde{\beta}_{2}^{*}$ are analyzed.

\subsubsection{Influence of performance adjustment coefficient on the optimal incentive coefficients}

In Equations (13) and (14), it is assumed that $\theta_{1}=0.7, \theta_{2}=$ $0.4, c=0.5, k=0.7, \tau=0.5, \delta_{1}=0.925, \gamma=0.8, d=0.7$ and $s=0.2$, the performance adjustment coefficient $l$ is valued within the range of $[0.567,1]$. The various relationships of the optimal incentive coefficients $\tilde{\beta}_{1}^{*}$ and $\tilde{\beta}_{2}^{*}$ to the performance adjustment coefficient $l$ are shown in Figure 2 .

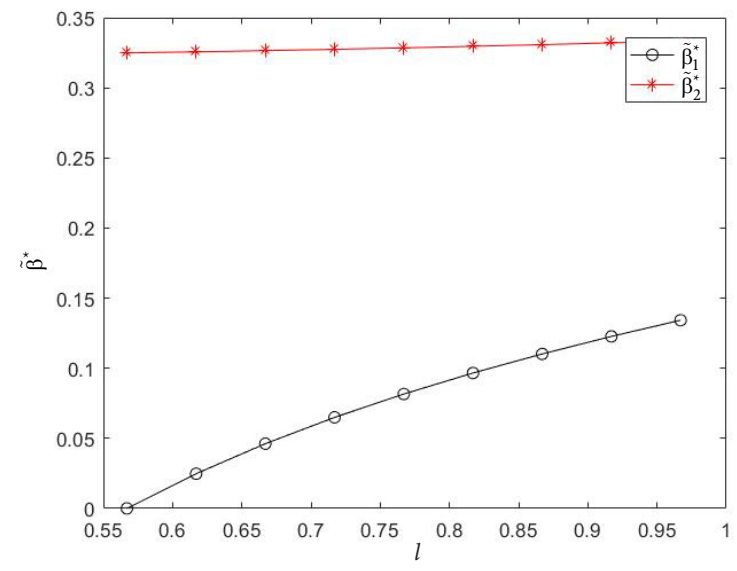

Figure 2. Relationships between performance adjustment coefficient and optimal incentive coefficients
It can be seen from Figure 2 that the optimal incentive coefficient $\tilde{\beta}_{1}^{*}$ in the first cycle is positively correlated with the performance adjustment coefficient $l$. The optimal incentive coefficient $\tilde{\beta}_{2}^{*}$ in the second cycle is almost not affected by the performance adjustment coefficient $l$. In the first performance assessment cycle, due to reputation and ratchet effects, a more extensive performance adjustment coefficient means that the higher the performance standard set by the public sector, and the lower the performance income for the private sector. In order to achieve reasonable returns for the private sector, the public sector needs to increase the incentives to the private sector. In the last cycle, the reputation and ratchet effects fail. So the performance adjustment coefficient hardly affects the optimal incentive coefficient anymore.

\subsubsection{Influence of bargaining power on the optimal incentive coefficient}

In Equations (13) and (14), it is assumed that $\theta_{1}=0.7$, $\theta_{2}=0.4, c=0.5, k=0.7, \delta_{1}=0.925, l=0.8, \tau=0.5$, $\gamma=0.8$ and $d=0.7$, the bargaining power $s$ of the private sector is valued within the range $[0,0.2141]$. The variation relationship between the optimal incentive coefficients $\tilde{\beta}_{1}^{*}$ and $\tilde{\beta}_{2}^{*}$ and the bargaining power $s$ is shown in Figure 3. It can be seen that the optimal incentive coefficient $\tilde{\beta}_{1}^{*}$ in the first cycle is negatively related the bargaining power $s$. In the second cycle, the bargaining power $s$ of the private sector has little effect on the optimal incentive coefficient $\tilde{\beta}_{2}^{*}$.

In summary, in the first cycle, due to reputation and ratchet effects, the stronger the bargaining power of the private sector is, the better the reputation effect is. And even if the government does not give much incentive, the private sector will actively improve the performance level to maintain its good reputation. In the last performance assessment cycle, neither reputation nor ratchet effects play a role. The bargaining power of the private sector has little effect on the optimal incentive coefficient.

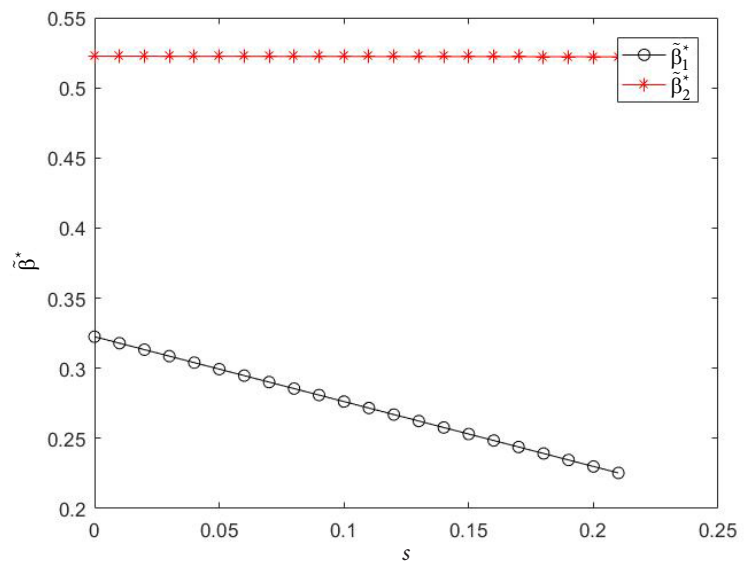

Figure 3. Relationships between bargaining power and optimal incentive coefficients 
3.2.3. Influence of the probability that the government finds the real performance level on the optimal incentive coefficients

In Equations (13) and (14), it is assumed that $\theta_{1}=0.7$, $\theta_{2}=0.4, c=0.5, k=0.7, \delta_{1}=0.925, l=0.8, \tau=0.5$, $s=0.2$ and $d=0.7$, the probability $\gamma$ that the government finds the real performance is valued within the range of $[0.5,1]$. The relationships between the optimal incentive coefficients $\tilde{\beta}_{1}^{*}$ and $\tilde{\beta}_{2}^{*}$ and the probability $\gamma$ are shown in Figure 4. It can be seen that the optimal incentive coefficient $\tilde{\beta}_{1}^{*}$ in the first cycle is positively correlated with the probability $\gamma$. The second cycle optimal incentive coefficient $\tilde{\beta}_{2}^{*}$ is almost not affected by the probability $\gamma$.

It can be observed that, the greater the probability that the government finds the real performance level in the first cycle is, the greater that the government has a sound monitoring mechanism. The more the private sector needs to actively work to improve performance and minimize the degree of performance manipulation, the greater the government's optimal incentive is. In the second and final cycle, both the reputation and ratchet effects lose their effect. Thus, the probability has little effect on the optimal incentive coefficient.

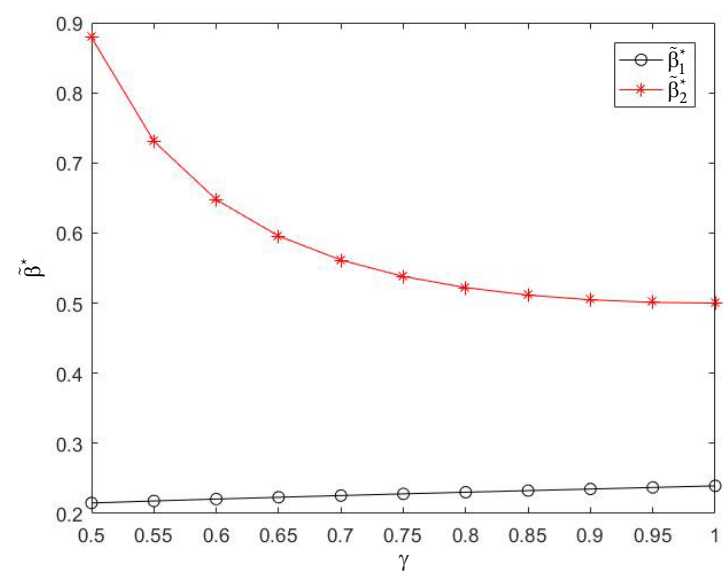

Figure 4. Relationships between the probability that the government finds the real performance level and the optimal incentive coefficients

\subsubsection{Influence of punishment coefficient on the optimal incentive coefficients}

In Equations (13) and (14), it is assumed that $\theta_{1}=0.7$, $\theta_{2}=0.4, c=0.5, k=0.7, \delta_{1}=0.925, l=0.8, \tau=0.5$, $s=0.2$ and $\gamma=0.8$, the punishment coefficient $d$ is valued within the range of $[0.5617,1]$. The punishment coefficient $d$ indicates that the government imposes a penalty to the private sector because of the performance manipulation behavior. The relationships of the optimal incentive coefficients $\tilde{\beta}_{1}^{*}$ and $\tilde{\beta}_{2}^{*}$ to the punishment coefficient $d$ are shown in Figure 5.

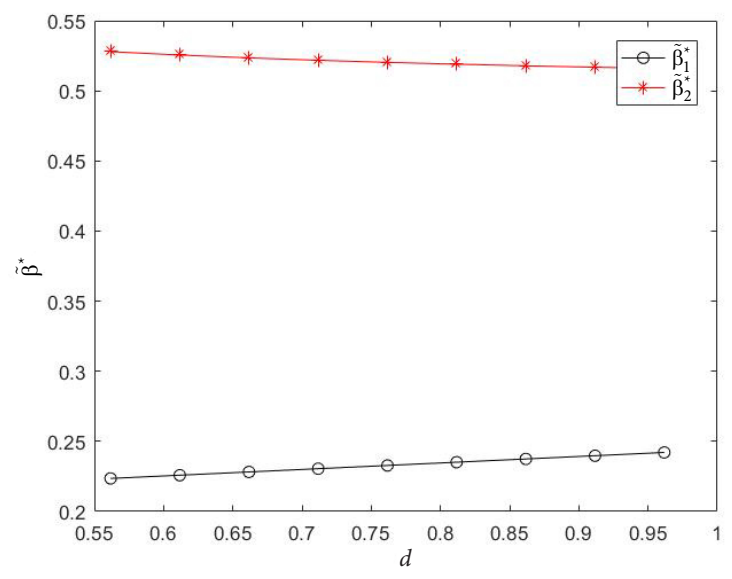

Figure 5. Relationships between punishment coefficient and optimal incentive coefficients

It can be seen from Figure 5 that the optimal incentive coefficient $\tilde{\beta}_{1}^{*}$ in the first cycle is positively correlated with the punishment coefficient $d$. In the second cycle, the optimal incentive coefficient $\tilde{\beta}_{2}^{*}$ is almost not affected by the punishment coefficient.

\section{Simulation and case analysis}

Nowadays, PPP mode is widely used to the cooperation projects between government and enterprise, in which government hopes to maximize social benefits, and private sector would like to maximize its profit (Wang et al., 2018). While the higher the performance level means that the private sector will invest more in the operation and maintenance process of the project, that is, the higher the cost to be paid. The profit seeking nature of the private sector may reduce the investment as much as possible in the construction and operation and maintenance process of the project, even at the expense of reducing the social benefits of the project, and if the social capital party has no stable economic income in the project, and their enthusiasm to participate in the project will also be reduced.

This section will give a simulation analysis based on a water environment governance and ecological restoration PPP project in China with the total investment 2162.6205 million Yuan. The estimated cooperation period of this project is 20 years, which includes 2 years of construction period and 18 years of operation and maintenance period. The private sector is paid by the government according to performance evaluation scores in the operation and maintenance process. The private sector obtains economic benefits through the operation and maintenance of the project. It is assumed that the government has set up a relatively perfect supervision mechanism during the operation and maintenance period of the project, and once it is found that the performance level of the private sector is untrue, it will be severely punished. Using the proposed model, the different scenarios are listed in the following subsections. 


\subsection{Influence of the input of the private sector on the optimal incentive coefficients}

In Equations (13) and (14), it is assumed that $c=0.5$, $k=0.7, d=0.7, \delta_{1}=0.925, l=0.8, \tau=0.5, s=0.2$ and $\gamma=0.8$. The influence of the input $\theta_{1}$ and $\theta_{2}$ of the private sector in two performance assessment cycles on the optimal incentive coefficients $\tilde{\beta}_{1}^{*}$ and $\tilde{\beta}_{2}^{*}$ is analyzed in two conditions. For convenience, $\tilde{\beta}^{*}$ and $\theta$ indicate the set of optimal incentive coefficients and inputs, i.e. $\tilde{\beta}^{*}=\left\{\tilde{\beta}_{1}^{*}, \tilde{\beta}_{2}^{*}\right\}$ and $\theta=\left\{\theta_{1}, \theta_{2}\right\}$.

\subsubsection{The input of the private sector in two cycles is the} same

The input of the private sector in the two cycles is the same level, that is $\theta_{1}=\theta_{2}=\theta$. The values of other parameters are substituted into Equations (13) and (14). According to $0<\tilde{\beta}_{1}^{*}<1$ and $0<\tilde{\beta}_{2}^{*}<1$, it can be known that $\theta$ is valued within the range of $[0.7028,1]$, and the relationships of $\theta$ and $\tilde{\beta}_{1}^{*}, \tilde{\beta}_{2}^{*}$ are shown in Figure 6 .

As Figure 6 shown, when the input of the private sector in different cycles are the same, $\tilde{\beta}_{2}^{*}>\tilde{\beta}_{1}^{*}$. The optimal incentive coefficient $\tilde{\beta}_{1}^{*}$ of the first cycle is directly proportional to the input $\theta$; and the optimal incentive coefficient $\tilde{\beta}_{2}^{*}$ of the second cycle has no apparent correlation with the input $\theta$.

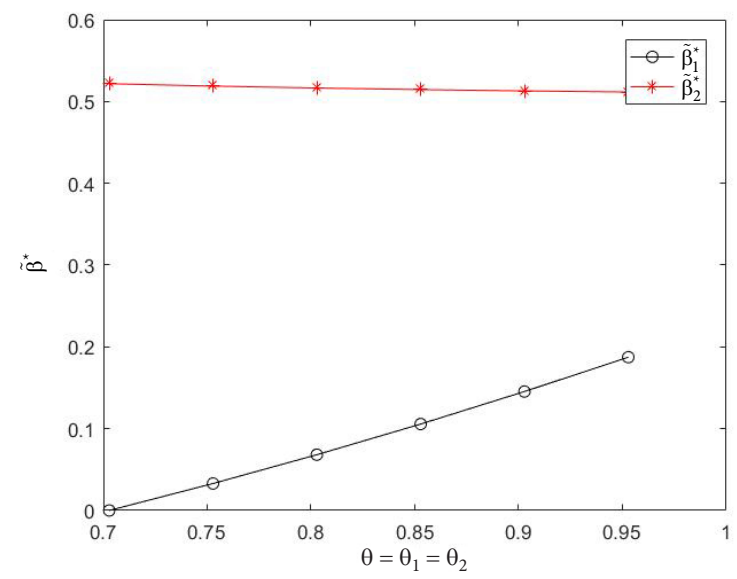

Figure 6. Relationship of input and optimal incentive coefficient when the input is the same in two cycles

\subsubsection{The inputs in two cycles are different}

The inputs of the private sector in the two cycles are different, that is $\theta_{1} \neq \theta_{2}$. The values of all parameters are substituted into Equations (13) and (14). According to $0<\tilde{\beta}_{1}^{*}<1$ and $0<\tilde{\beta}_{2}^{*}<1$, the values of $\theta_{1}$ and $\theta_{2}$ are shown in Table 3. To visualize the influence of the change in $\theta_{1}$ and $\theta_{2}$, the results are represented in Figure 7.

As Figure 7 showing, the input $\theta_{1}>\theta_{2}$ and the optimal incentive coefficient $\tilde{\beta}_{2}^{*}>\tilde{\beta}_{1}^{*}$. When the input $\theta_{2}$ of the private sector in the second cycle of is fixed, the optimal incentive coefficient $\tilde{\beta}_{1}^{*}$ is directly proportional to the input $\theta_{1}$ in the first cycle. The optimal incentive
Table 3. Values of inputs in different cycles

\begin{tabular}{|c|c|c|c|}
\hline$\theta_{2}$ & $\theta_{1}$ & $\tilde{\beta}_{1}^{*}$ & $\tilde{\beta}_{2}^{*}$ \\
\hline 0.1 & {$[0.2074,1]$} & $0<\tilde{\beta}_{1}^{*}<1$ & $0<\tilde{\beta}_{2}^{*}<1$ \\
\hline 0.2 & {$[0.2537,1]$} & $0<\tilde{\beta}_{1}^{*}<1$ & $0<\tilde{\beta}_{2}^{*}<1$ \\
\hline 0.3 & {$[0.3783,1]$} & $0<\tilde{\beta}_{1}^{*}<1$ & $0<\tilde{\beta}_{2}^{*}<1$ \\
\hline 0.4 & {$[0.5003,1]$} & $0<\tilde{\beta}_{1}^{*}<1$ & $0<\tilde{\beta}_{2}^{*}<1$ \\
\hline 0.5 & {$[0.6189,1]$} & $0<\tilde{\beta}_{1}^{*}<1$ & $0<\tilde{\beta}_{2}^{*}<1$ \\
\hline 0.6 & {$[0.7337,1]$} & $0<\tilde{\beta}_{1}^{*}<1$ & $0<\tilde{\beta}_{2}^{*}<1$ \\
\hline 0.7 & {$[0.8441,1]$} & $0<\tilde{\beta}_{1}^{*}<1$ & $0<\tilde{\beta}_{2}^{*}<1$ \\
\hline 0.8 & {$[0.9499,1]$} & $0<\tilde{\beta}_{1}^{*}<1$ & $0<\tilde{\beta}_{2}^{*}<1$ \\
\hline
\end{tabular}

coefficient $\tilde{\beta}_{2}^{*}$ in the second cycle is inversely proportional to the input $\theta_{1}$. But when the input $\theta_{2}$ is greater than or equal to 0.5 , there is no correlation between the optimal incentive coefficient $\tilde{\beta}_{2}^{*}$ and input $\theta_{1}$.

It can be seen that the input of private sector in the first performance assessment cycle is greater than or equal to its input in the second cycle. When the input is considered only, the optimal incentive coefficient in the first cycle is always smaller than it in the second cycle; the optimal incentive coefficient in the first cycle is directly proportional to the input; and the optimal incentive coefficient in the second cycle is inversely proportional to the input. In the last cycle, the private sector will reduce its input as there is no further performance constraint. Therefore, the government should increase incentives to motivate the private sector increase the input. However, the incentive effect will be ineffective when the input increases to 0.5 . In order to reduce the risk of residual value of PPP projects, the government should strengthen the supervision and control of the last performance assessment cycle of the franchise period.

\subsection{Influence of the probability that the government finds the real performance level and the performance adjustment coefficient on the optimal incentive coefficients}

In Equations (13) and (14), it is assumed that $\theta_{1}=0.7, \theta_{2}=$ $0.4, c=0.5, k=0.7, \delta_{1}=0.925, d=0.7, \tau=0.5$ and $s=0.2$. Because $0<\tilde{\beta}_{1}^{*}<1$ and $0<\tilde{\beta}_{2}^{*}<1$, the $\gamma$ and the $l$ are valued within the ranges of $[0.472,1]$ and $[0.3755,0.9]$, respectively. Therefore, the relations of the probability $\gamma$ and the performance adjustment coefficient $l$ on the optimal incentive coefficients $\tilde{\beta}_{1}^{*}$ and $\tilde{\beta}_{2}^{*}$ is shown in Figure 8. It can be observed that when the given parameters is valued, there is always $\tilde{\beta}_{1}^{*}<\tilde{\beta}_{2}^{*}$. Based on the joint influence of the probability $\gamma$ and the performance adjustment coefficient $l$, 


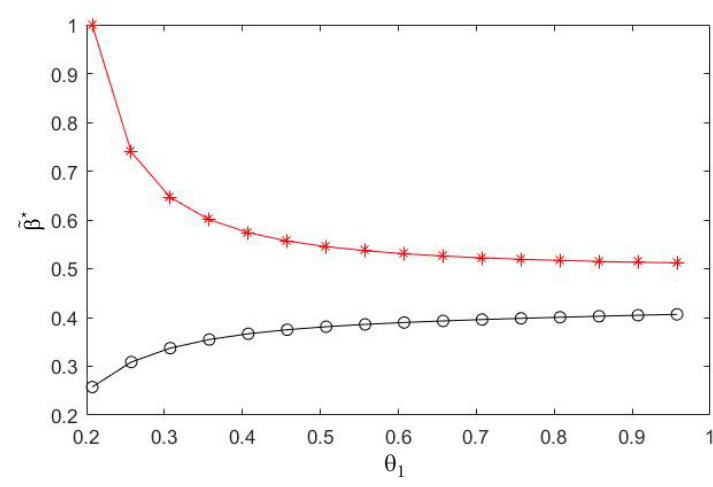

$\multimap \tilde{\beta}_{1}^{*}\left(\theta_{2}=0.1\right) \rightarrow \tilde{\beta}_{2}^{*}\left(\theta_{2}=0.1\right)$

a)

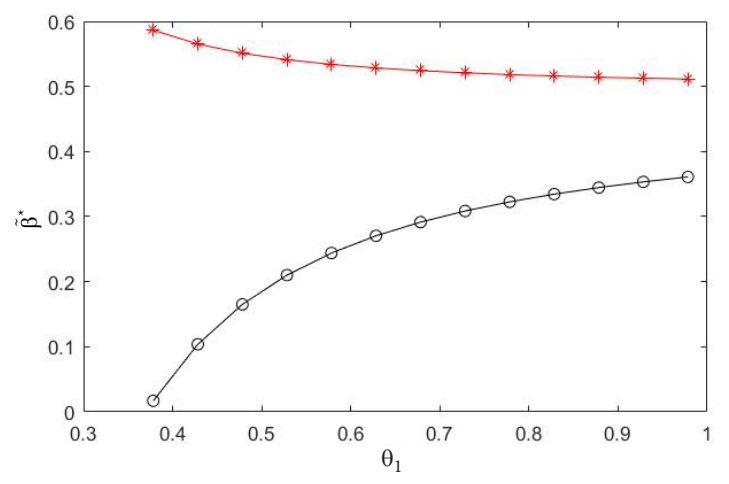

$\multimap \tilde{\beta}_{1}^{*}\left(\theta_{2}=0.3\right) \rightarrow \tilde{\beta}_{2}^{*}\left(\theta_{2}=0.3\right)$

c)

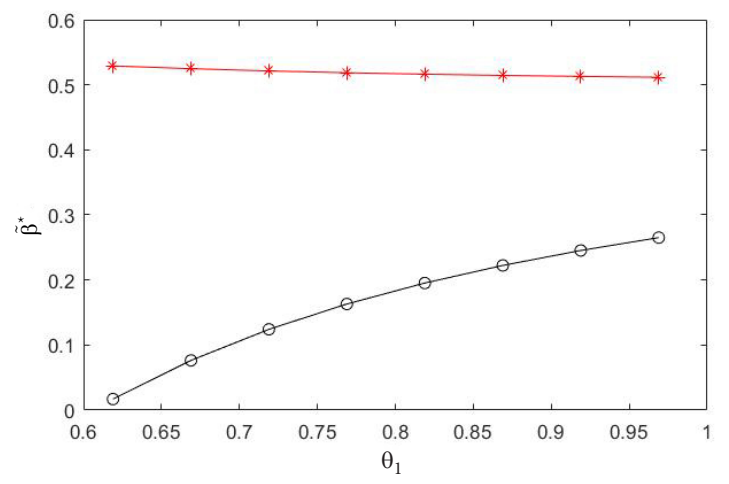

$$
\multimap \tilde{\beta}_{1}^{*}\left(\theta_{2}=0.5\right) \rightarrow \tilde{\beta}_{2}^{*}\left(\theta_{2}=0.5\right)
$$

e)

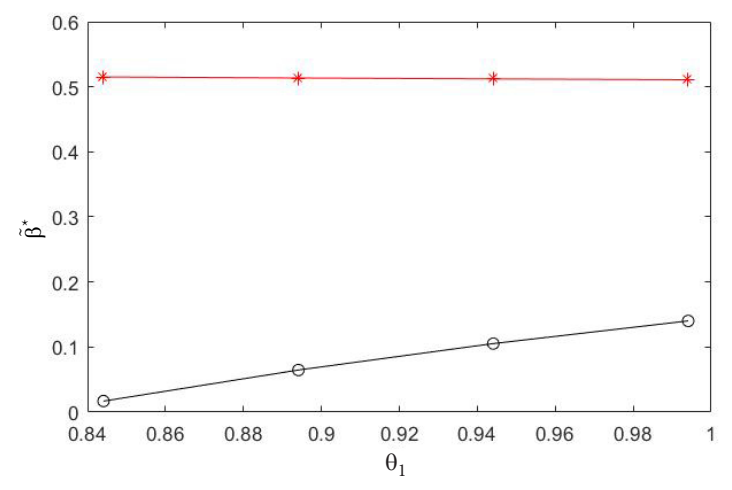

$$
\multimap \tilde{\beta}_{1}^{*}\left(\theta_{2}=0.7\right) \rightarrow \tilde{\beta}_{2}^{*}\left(\theta_{2}=0.7\right)
$$

g)

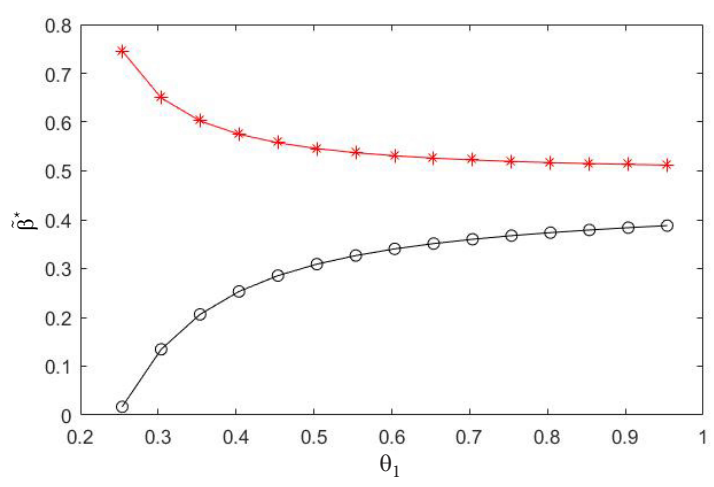

$\multimap \tilde{\beta}_{1}^{*}\left(\theta_{2}=0.2\right) \rightarrow \tilde{\beta}_{2}^{*}\left(\theta_{2}=0.2\right)$

b)

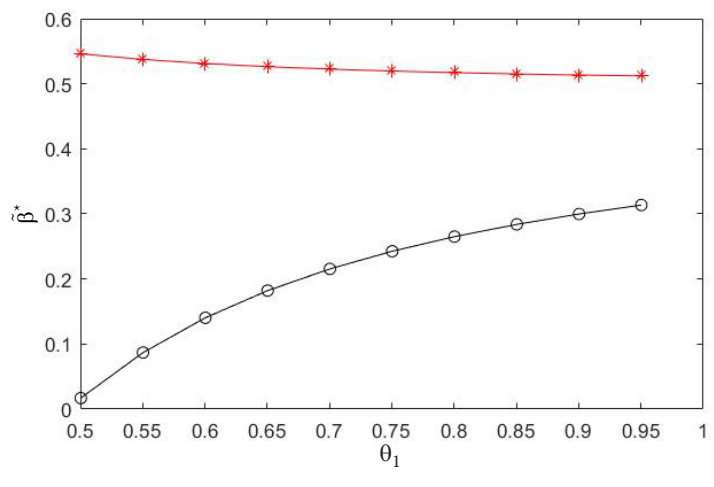

$\multimap \tilde{\beta}_{1}^{*}\left(\theta_{2}=0.4\right) \rightarrow \tilde{\beta}_{2}^{*}\left(\theta_{2}=0.4\right)$

d)

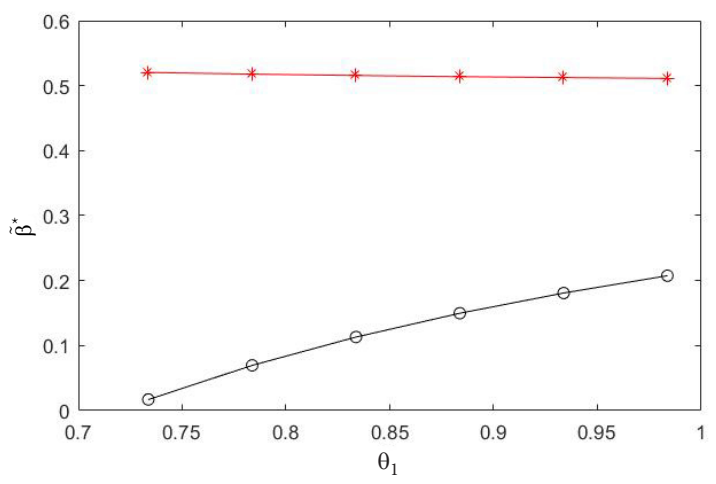

$\multimap \tilde{\beta}_{1}^{*}\left(\theta_{2}=0.6\right) \rightarrow \tilde{\beta}_{2}^{*}\left(\theta_{2}=0.6\right)$

f)

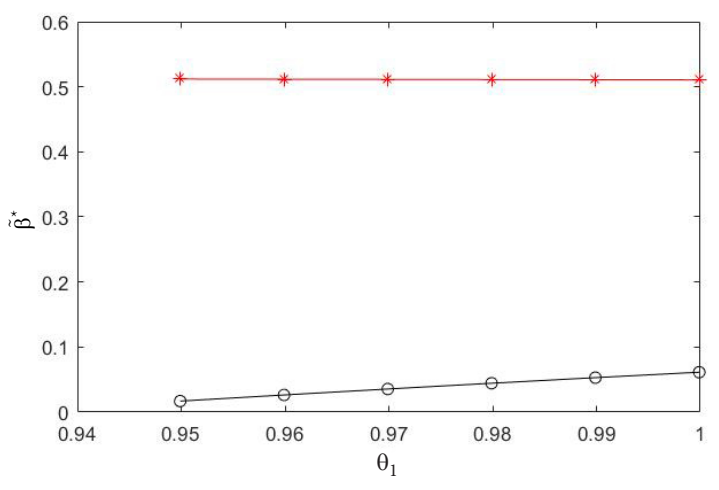

$\multimap \tilde{\beta}_{1}^{*}\left(\theta_{2}=0.8\right) \rightarrow \tilde{\beta}_{2}^{*}\left(\theta_{2}=0.8\right)$

h)

Figure 7. The effects of different inputs on optimal incentive coefficients 


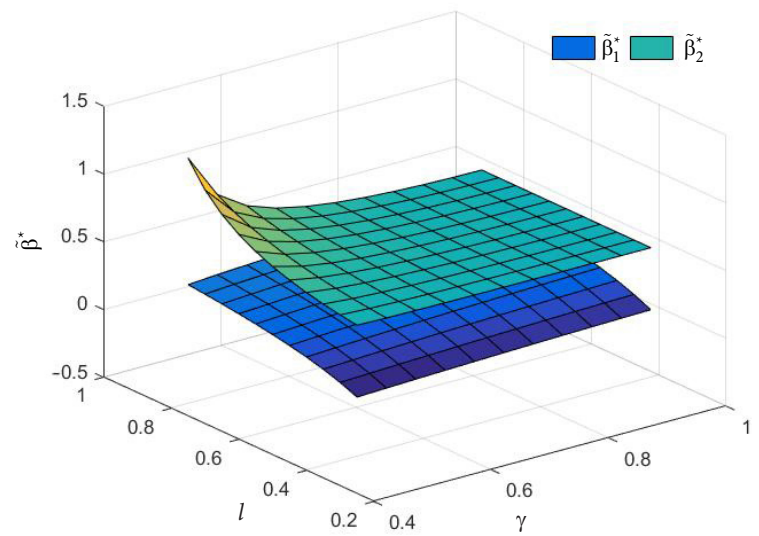

Figure 8 . The influence of the probability of true performance level found by the public and performance adjust coefficient on optimal incentive coefficients

the optimal incentive coefficient $\tilde{\beta}_{1}^{*}$ in the first cycle is increasing with the change of both parameters. The optimal incentive coefficient $\tilde{\beta}_{2}^{\star}$ in the second cycle is inversely proportional to the probability $\gamma$, and with no obvious correlation with the performance adjustment coefficient $l$.

From the analysis above, it can be known that under the joint influence of the probability that the government finds the real performance level and the performance adjustment coefficient, the optimal incentive coefficient in the first performance assessment cycle is less than that in the second cycle. An increase in probability implies an increase in the degree of the penalty imposed on the private sector. An increase in the performance adjustment coefficient implies an increase in the government's performance target, followed by a profit decrease for the private sector. Therefore, due to the role of reputation and ratchet effects the first cycle, the private sector will actively make efforts to meet the primary benefits and improve the income of future performance cycles even if the government does not pay too much incentive. However, the reputation and ratchet effects fail in the second cycle, and the government should increase the incentive strength to ensure the reasonable income of the private sector.

\subsection{Influence of the probability that the government finds the real performance level and the punishment coefficient on the optimal incentive coefficients}

It is assumed that $\theta_{1}=0.7, \theta_{2}=0.4, c=0.5, k=0.7, \delta_{1}=$ $0.925, l=0.8, \tau=0.5$ and $s=0.2$, and they are substituted into Equations (13) and (14). As $0<\tilde{\beta}_{1}^{*}<1$ and $0<\tilde{\beta}_{2}^{*}<1$, the $\gamma$ and $d$ are valued within the range of $[0.6,1]$ and $[0.4383,1]$, respectively. The relationships of $\gamma$ and $d$ between the $\tilde{\beta}_{1}^{*}$ and $\tilde{\beta}_{2}^{*}$ are shown in Figure 9. It can be observed that when the given parameters are valued, there is always $\tilde{\beta}_{1}^{*}<\tilde{\beta}_{2}^{*}$. Under the joint influence of the probability $\gamma$ and the punishment coefficient $d$, the optimal incentive coefficients $\tilde{\beta}_{1}^{*}$ and $\tilde{\beta}_{2}^{*}$ in the two cycles are increasing with the raising of the two parameters.

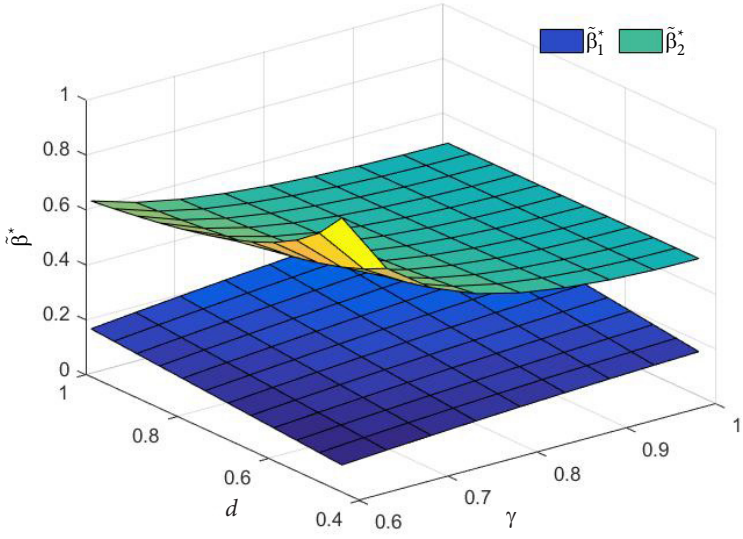

Figure 9. The effects of true performance level found by the public sector and punishment coefficient on optimal incentive coefficients

From the analysis above, it can be known that under the common influence of the probability that the government finds the real performance level and the punishment coefficient, the optimal incentive coefficient in the first performance assessment cycle is less than that in the second cycle.

An increase in probability implies an increase in the degree of the penalty imposed on the private sector. To reduce the adverse effects of the ratchet effect, governments need to increase penalties while increasing incentives. However, the reputation and ratchet effects fail in the second cycle. The private sector will reduce the enthusiasm of its efforts and even reduce the performance level as it cannot obtain adequate income. Therefore, the government should increase the incentive strength to ensure the reasonable income of the private sector and improve the social benefits of the infrastructure PPP project.

\subsection{Influence of bargaining power of the private sector and the performance adjustment coefficient with the optimal incentive coefficients}

It is assumed that $\theta_{1}=0.7, \theta_{2}=0.4, c=0.5, k=0.7, \delta_{1}=$ $0.925, \gamma=0.8, \tau=0.5$ and $d=0.7$, and they are substituted into Equations (13) and (14). As $0<\tilde{\beta}_{1}^{*}<1$ and $0<\tilde{\beta}_{2}^{*}<1$, the $s$ and $l$ are valued within the range of $[0,0.5324]$ and $[0.5,1]$, respectively. Therefore, the influence effects of the bargaining power $s$ of the private sector and the performance adjustment coefficient $l$ on the optimal incentive coefficients $\tilde{\beta}_{1}^{*}$ and $\tilde{\beta}_{2}^{*}$ are shown in Figure 10. It can be seen that when the given parameters are valued, there is always $\tilde{\beta}_{1}^{*}<\tilde{\beta}_{2}^{*}$. Under the joint influence of the bargaining power and the performance adjustment coefficient, the optimal incentive coefficient $\tilde{\beta}_{1}^{*}$ is increasing with the raising of the $s$ and $l$. The optimal incentive coefficient $\tilde{\beta}_{2}^{*}$ in the second cycle has no apparent correlation to the change of the $s$ and $l$.

From the analysis above, it can be known that the bargaining power is directly proportional to the reputation of the private sector. A larger performance adjustment 


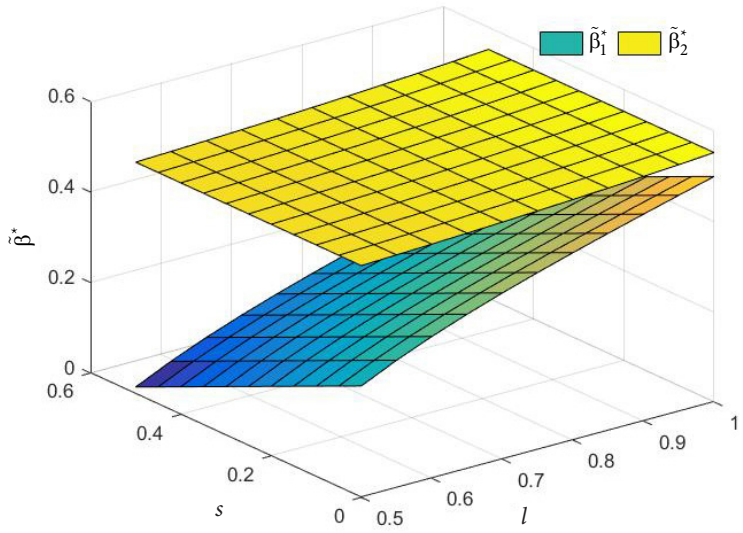

Figure 10. The effects of bargaining power and performance adjust coefficient on optimal incentive coefficients

coefficient implies a larger performance target set by the government and a subsequent reduction in profit for the private sector. In the first performance assessment cycle, due to the effect of reputation and ratchet effects, the private sector will actively make efforts to improve the project performance while meeting the basic benefits even if the government does not pay too much incentive. However, the reputation and ratchet effects fail in the second cycle. The government should increase the incentive strength to ensure the social benefits of the project. For the government, an effective method should be taken to measure the infrastructure output of social benefits and the input of the private sector, and determinate the incentive costs of the public sector. And the public sector should set the performance adjustment coefficient at a sound level in the first cycle, which will supervise the effort level of the private sector.

\subsection{Comparative analysis}

In order To illustrate the feasibility of this model, the model of considering only reputation effect and the model of considering reputation and ratchet effects simultaneously are compared in this section. When the influence of reputation effect is considered only, there is no performance manipulation behavior; the effort level of the private sector and the optimal incentive coefficient of the government are considered only. When the reputation effect is considered only, the optimal effort level of the private sector in the second performance assessment cycle is (Li et al., 2020b):

$$
\bar{e}_{2}^{*}=\frac{\bar{\beta}_{2} k \theta_{2}}{c},
$$

the optimal effort level of the private sector in the first cycle is (Li et al., 2020b):

$$
\bar{e}_{1}^{*}=\frac{\bar{\beta}_{1} k \theta_{1}+s \tau \delta k \theta_{1}}{c} \text {. }
$$

The optimal incentive coefficients of the two cycles ( $\mathrm{Li}$ et al., 2020b) are:

$$
\begin{aligned}
& \bar{\beta}_{1}^{*}=\frac{(1-2 s \tau \delta) k^{2} \theta_{1}^{2}+c \pi_{0}}{2 k^{2} \theta_{1}^{2}}, \\
& \bar{\beta}_{2}^{*}=\frac{k^{2} \theta_{2}^{2}+c \pi_{0}}{2 k^{2} \theta_{2}^{2}} .
\end{aligned}
$$

For convenience, the multi-period dynamic incentive mechanism model under the performance-based reputation effect is referred to as "Model one"; and the multiperiod dynamic incentive mechanism model under coupling effect performance-based reputation and ratchet is referred to as "Model two".

It can be seen from Equations (17) and (18) that the variation of the bargaining power $s$ in Model one is only related to the optimal incentive coefficient $\bar{\beta}_{1}^{*}$ in the first cycle, and does not correlate with the optimal incentive coefficient $\bar{\beta}_{2}^{*}$. In Model two, the main parameters of the bargaining power $s$, the performance adjustment coefficient $l$, the probability $\gamma$ that the government finds the real performance level, and the punishment coefficient $d$ are only related to the optimal incentive coefficient $\bar{\beta}_{1}^{*}$, and have no obvious correlation with the incentive coefficient $\bar{\beta}_{2}^{*}$. Therefore, the variation trends of the optimal incentive coefficients $\bar{\beta}_{1}^{*}$ and $\tilde{\beta}_{1}^{*}$ of the two models in the first cycle under the influence of the parameters are analyzed in steps.

Step 1: Assign values to the parameters in the two models, and let $\theta_{1}=0.7, \theta_{2}=0.4, c=0.5, k=0.7, \delta_{1}=\delta=$ $0.925, \tau=0.5$ and $\pi_{0}=0.6$, respectively.

Step 2: Analyze the variation trends of the optimal incentive coefficients $\bar{\beta}_{1}^{*}$ and $\tilde{\beta}_{1}^{*}$ in the two models under the influence of the bargaining power $s$, the performance adjustment coefficient $l$, the probability $\gamma$, and the punishment coefficient $d$.

\subsubsection{Influences of bargaining power and performance adjustment coefficient on $\bar{\beta}_{1}^{*}$ and $\tilde{\beta}_{1}^{*}$}

In the first step, the values of all parameters are substituted into the Equations (11), (13) and (14), respectively. According to $0<\bar{\beta}_{1}^{*}<1,0<\tilde{\beta}_{1}^{*}<1$ and $0<\tilde{\beta}_{2}^{*}<1$, the $s$ and $l$ are valued within the range of $[0.2697,0.5324]$ and $[0.5,1]$, respectively. The variations of $\bar{\beta}_{1}^{*}$ and $\tilde{\beta}_{1}^{*}$ under the joint influence $s$ and $l$ are shown in Figure 11. It can be seen that when the values of other influencing parameters are determined, there is always $\tilde{\beta}_{1}^{*}<\bar{\beta}_{2}^{*}$ under joint influence of $s$ and $l$. The $\bar{\beta}_{1}^{*}$ and $\bar{\beta}_{1}^{*}$ are decreasing with the increasing of barging power $s ; \tilde{\beta}_{1}^{*}$ is increasing with the raising of performance adjustment coefficient $l$; and the $\tilde{\beta}_{1}^{*}$ is in the trend of increasing under the joint effect of $s$ and $l$.

In conclusion, the optimal incentive coefficients $\tilde{\beta}_{1}^{*}$ and $\bar{\beta}_{1}^{*}$ are influenced by the bargaining power of the private sector. The $\tilde{\beta}_{1}^{*}$ is also influenced by the performance adjustment coefficient. In the first performance assessment cycle, the optimal incentive coefficient in Model one is only affected by the reputation effect, some parts of incentives are replaced with the reputation, and 


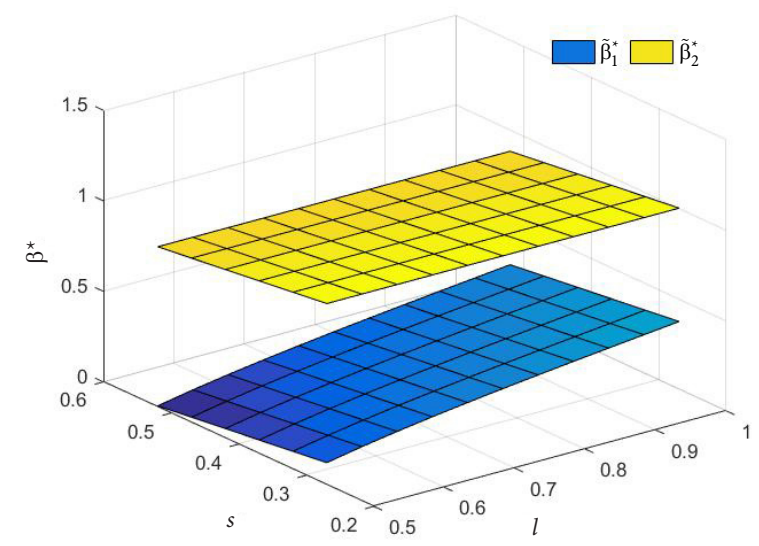

Figure 11. The comparative relationship between two optimal incentive coefficients with the effects of bargaining power and performance adjust coefficient

the incentive cost of the government can be reduced. For Model two, the optimal incentive coefficient is influenced by reputation and ratchet effects. The optimal incentive coefficient $\tilde{\beta}_{1}^{*}$ under the influences of bargaining power and performance adjustment coefficient is increasing. The increasing performance adjustment coefficient would enhance the ratchet effects, and probably stronger than the reputation effect. Under the influence of the coupling of reputation and ratchet effects, the ratchet effect weakens the reputation effect. If the government raises performance targets through performance adjustment factors, the government should increase incentives to achieve the expected goals. So the public sector should make the performance adjustment coefficient at a sound level.

\subsubsection{Influence of bargaining power and probability} that the government finds real performance level on $\tilde{\beta}_{1}^{*}$ and $\bar{\beta}_{1}^{*}$

The values assigned to each parameter in the first step are substituted into Equations (11), (13) and (14), respectively. According to $0<\bar{\beta}_{1}^{*}<1,0<\tilde{\beta}_{1}^{*}<1$ and $0<\tilde{\beta}_{2}^{*}<1$, the $s$ and $\gamma$ are valued within the range of $[0.2697,1]$ and $[0.6058,1]$, respectively. The variation of $\tilde{\beta}_{1}^{*}$ and $\bar{\beta}_{1}^{*}$ under the joint influence of the bargaining power $s$ and the probability $\gamma$ is shown in Figure 12. It can be seen that there is always $\tilde{\beta}_{1}^{*}<\bar{\beta}_{1}^{*}$. When the values of other parameters are determined, $\bar{\beta}_{1}^{*}$ and $\tilde{\beta}_{1}^{*}$ would reduce with the increasing of $s ; \tilde{\beta}_{1}^{*}$ would increasing with the raising of $\gamma$. Also, the $\tilde{\beta}_{1}^{*}$ is in the trend of decrease under the joint influence of the bargaining power $s$ and the probability $\gamma$. As the influence of the ratchet effect on incentive coefficient is no considered in Model one, there is no correlation between the $\bar{\beta}_{1}^{*}$ and $\gamma$.

From the analysis above, it can be known that the optimal incentive coefficients $\bar{\beta}_{1}^{*}$ and $\tilde{\beta}_{1}^{*}$ are influenced by the bargaining power of the private sector. The $\tilde{\beta}_{1}^{*}$ is also influenced by probability $\gamma$. The optimal incentive coefficient $\tilde{\beta}_{1}^{*}$ under the joint influence of the $s$ and $\gamma$ is in the trend of decrease. For Model one, in the first cycle,

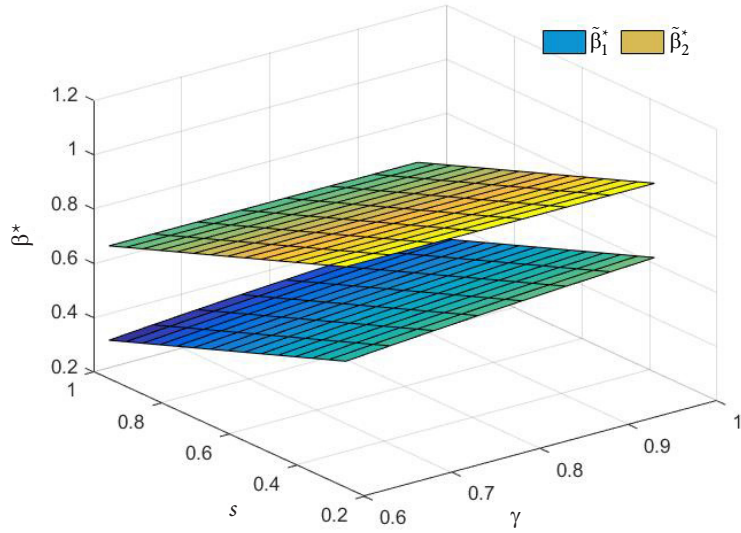

Figure 12. The comparative relationship between optimal incentive coefficients and the bargaining power and the probability that the government finds real performance level

the optimal incentive coefficient is only affected by the reputation effect. A part of the incentive effect is replaced with the reputation, which reduced the incentive cost of the government. For Model two, the optimal incentive coefficient under the influence of bargaining power and probability. Under the influence of coupled reputation and ratchet effects, the reputation effect is stronger because it weakens the ratchet effect, which effectively reduces the government's incentive costs in the incentive process.

\subsubsection{Influence of bargaining power and punishment coefficient on $\tilde{\beta}_{1}^{*}$ and $\bar{\beta}_{1}^{*}$}

The values assigned to each parameter in the first step are substituted into Equations (11), (13) and (14). According to $0<\bar{\beta}_{1}^{*}<1,0<\tilde{\beta}_{1}^{*}<1$ and $0<\tilde{\beta}_{2}^{*}<1$, the $s$ and $d$ are valued within the range of $[0.2697,0.6641]$ and $[0,1]$, respectively. The variation of the optimal incentive coefficients $\tilde{\beta}_{1}^{*}$ and $\bar{\beta}_{1}^{*}$ under the joint influence of $s$ and $d$ is shown in Figure 13. It can be seen that there is always $\tilde{\beta}_{1}^{*}<\bar{\beta}_{1}^{*}$. When the values of other parameters are determined, the optimal incentive coefficients $\tilde{\beta}_{1}^{*}$ and $\bar{\beta}_{1}^{*}$ are decreasing

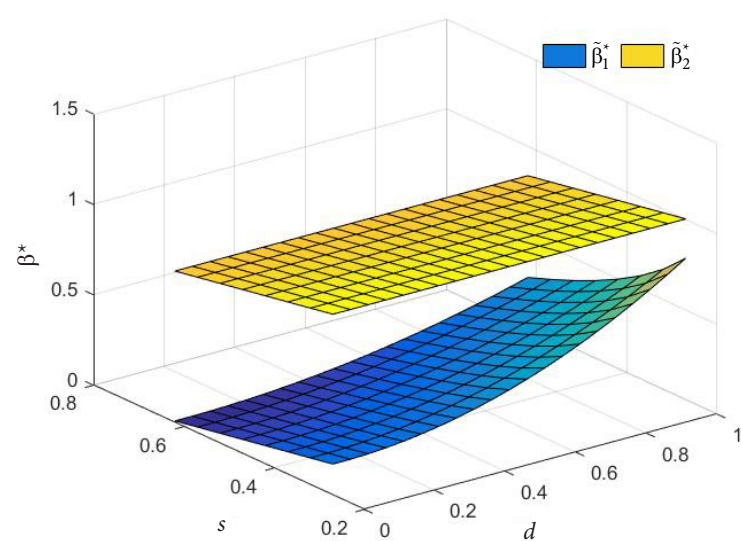

Figure 13. Comparative relationships between optimal incentive coefficients of the two and bargaining power and punishment coefficient 
with the raising of $s$. The optimal incentive coefficient $\tilde{\beta}_{1}^{*}$ is increasing with the raising of $d$. In Model two, under the joint influence of $s$ and $d$, the optimal incentive coefficient $\tilde{\beta}_{1}^{*}$ is in the trend of increase first and then decrease. In Model one, there is no ratchet effect, so $\bar{\beta}_{1}^{*}$ is no related with $d$.

These results show that the optimal incentive coefficients $\tilde{\beta}_{1}^{*}$ and $\bar{\beta}_{1}^{*}$ are influenced by the bargaining power. The optimal incentive coefficient $\tilde{\beta}_{1}^{*}$ is also influenced by the punishment coefficient. In Model two, under the joint influence of bargaining power and punishment coefficient, the optimal incentive coefficient $\tilde{\beta}_{1}^{*}$ is in the trend of decrease first and then increase. In the first performance assessment cycle, the bargaining power of the private sector is directly proportional to the reputation. A part of the incentive effect is replaced with the reputation effect, which reduces the incentive cost of the government. For Model two, when the bargaining power and the punishment coefficient are small, the reputation effect is stronger, so the incentive should be reduced. When the bargaining power and the punishment coefficient are gradually increasing, the ratchet effect will weaken the reputation effect. In order to prevent the incentive incompatibility caused by the ratchet effect, the government should increase the incentive while increasing the punishment to achieve the "distinguish clearly between reward and punishment".

\subsection{Management implication}

There are some implications to the public sector from following aspects. (1) The income of the private sector is divided into fixed income and performance-based income (variable income), where the fixed income is determined by the performance output and reputation of the previous cycles, and the performance-based income (variable income) of the private sector is affected by the coefficient of social benefit output. Under information asymmetry between the government and the private sector, the government should take an effective method to measure the infrastructure output of social benefits and the input of the private sector, which would help to reduce the incentive costs of the public sector. In other words, the existence of the reputation effect would reduce the incentive cost of the government and realizes Pareto improvement. (2) In the first cycle, due to the existence of ratchet effect, the higher performance adjustment coefficient set by the government will reduce the effort level of the private sector. So the public sector should set the performance adjustment coefficient at a sound level, which would rise slowly. (3) The manipulation degree of the private sector is negatively correlated with the probability that the government finds the real performance level, the bargaining power of the private sector and the punishment coefficient set by the government. To prevent the adverse effects of the ratchet effect, the government needs to increase regulation and penalties and amplify the impact of the reputation effect. This would achieve incentive compatibility and prevent "whip the fast and hard-working".

\section{Conclusions}

The performance-based payment PPP model is widely used in infrastructure projects. The existing research only consider the performance-based reputation mechanisms, but the ratchet effect generated by performance-based incentives has been neglected. The major innovation is that to complete the design of performance-based incentives mechanisms, this study constructed multi-period dynamic incentive mechanism model based on coupling with the performance-based reputation effect and ratchet effect. And the optimal effort level and deflated performance manipulation degrees for private sector and optimal incentive coefficients were analyzed, respectively. Finally, the results of the model are discussed through numerical simulation.

The results of this study are as follows: (1) Due to the reputation effect in the first performance assessment cycle, the private sector will make active efforts to improve performance to improve the income of the future cycles even if the expected target performance set by the government is relatively rising; (2) Under the coupling of reputation and ratchet effects, the optimal incentive coefficient in the last performance assessment cycle is always greater than that of the first cycle. On the one hand, the reputation and ratchet effects fail in the last cycle, and the performance adjustment coefficient, bargaining power, probability punishment coefficient all affect the incentive coefficient; On the other hand, in the first cycle, the parameters related to the ratchet effect (including the performance adjustment coefficient, the probability, the punishment coefficient) are positively correlated with the optimal incentive coefficient; (3) With the coupling case of reputation and ratchet effects, the optimal incentive coefficient will vary with different stimulating parameters worked for the design of the incentives performance-based incentives mechanisms; (4) Bargaining power for the private sector has a negative influence on the optimal incentive coefficient. These show that if the government wants to improve performance standards and prevent the occurrence of the ratchet effect in the multi-period dynamic incentive model, it should strengthen the regulation to increase the probability of finding the real performance of the private sector, and the intensity of punishment. Moreover, more significant incentives are also needed to be given to the private sector to work towards the rising performance standards.

The coupling effect of reputation and ratchet determines the incentive policy. Firstly, from the coupling effect of bargaining power and performance regulation coefficient, because of the ratchet effect, if the government wants to improve performance targets through performance adjustment coefficients, it needs to increase incentives. Secondly, from the coupling effect of the bargaining power and the probability, the government needs to increase incentives to achieve "reward and punish". The principal reason is that the optimal incentive coefficients will increase with the raising of the 
two parameters and shows an overall increasing trend. The greater the probability is, the greater the penalty imposed by the government on the private sector is. And the bargaining power representing the reputation mechanism (implicit incentive) can replace part of the incentive effect (explicit incentive). Thirdly, from the coupling effect of the bargaining power and punishment coefficient, to prevent the incentive incompatibility caused by the ratchet effect, the government should increase the incentive while increasing the punishment to achieve the "penalties and rewards".

There are some limitations associated with this study. The coupling effect of reputation and ratchet effects in a multi-period dynamic incentive model is a complexity problem, which is jointly influenced by some parameters. These parameters should be discussed in a more multidimensional space. As the social output coefficient and degree of performance manipulation are difficult to quantify using existing studies, data could be collected in real life projects, the law of incentives could be written into specific contractual clauses. The results obtained in this study provide a new theoretical reference for the sustainability development of cooperation between government and private sector. By analyzing the internal impact of the coupling effect both of reputation and ratchet on payment from government, it can provide a reference for the decision-making of government and private sector in PPP projects. However, the research on the performancebased mechanism is still improving. At present, there is no complete system to measure the incentive coefficient of participants. At the same time, the game is a dynamic process, which means that the performance and strategy of the government and private sector are changing in the process of cooperation. Therefore, the research on these is the future research direction. A couple of simulations based on a practical case are worked out, and some results can be obtained from the process of simulations, which can provide certain theoretical reference for government.

\section{Data availability}

The data used to support the findings of this study are available from the corresponding author upon request.

\section{Funding}

The authors acknowledge with gratitude the MOE (Ministry of Education in China) Project of Humanities and Social Sciences (No. 19YJC630078), the National Key R\&D Program of China (No. 2018YFC0406905); Youth Talents Teachers Scheme of Henan Province Universities (No.2018GGJS080), the National Natural Science Foundation of China (No. 71974056 and 71302191), the Foundation for Distinguished Young Talents in Higher Education of Henan (Humanities \& Social Sciences), China (No. 2017-cxrc-023), China Scholarship Council (No. 201908410388). This study would not have been possible without their financial support.

\section{Author contributions}

Huimin Li and Limin Su conceived the study and were responsible for the design and development of the data analysis. Jian Zuo and Xianbo Zhao were responsible for data collection and analysis. Ruidong Chang and Fuqiang Wang wrote the first draft of the article.

\section{Disclosure statement}

The authors declare that they have no conflicts of interest.

\section{References}

Arbulu, I., Lozano, J., \& Rey-Maquieira, J. (2017). The challenges of tourism to waste-to-energy public-private partnerships. Renewable and Sustainable Energy Reviews, 72, 916-921. https://doi.org/10.1016/j.rser.2017.01.036

Beyer, A., Guttman, I., \& Marinovic, I. (2014). Optimal contracts with performance manipulation. Journal of Accounting Research, 52(4), 817-847.

https://doi.org/10.1111/1475-679X.12058

Bouwens, J., \& Kroos, P. (2011). Target ratcheting and effort reduction. Journal of Accounting \& Economics, 51(1-2), 171185. https://doi.org/10.1016/j.jacceco.2010.07.002

Charness, G., Kuhn, P., \& Villeval, M. C. (2011). Competition and the ratchet effect. Journal of Labor Economics, 29(3), 513-547. https://doi.org/10.1086/659347

Cheng, Z., Ke, Y., Lin, J., Yang, Z., \& Cai, J. (2016). Spatiotemporal dynamics of public private partnership projects in China. International Journal of Project Management, 34(7), 1242-1251. https://doi.org/10.1016/j.ijproman.2016.05.006

Choi, J. P., \& Thum, M. (2003). The dynamics of corruption with the ratchet effect. Journal of Public Economics, 87(3-4), 427443. https://doi.org/10.1016/S0047-2727(01)00149-9

Deng, X., Xiong, W., Yuan, J., \& Li, Q. (2009). Dynamic pricing and subsidy model for PPP projects based on satisfaction of participants. Journal of Southeast University. Natural Science Edition, 39(6), 1252-1257.

Domingues, S., \& Zlatkovic, D. (2015). Renegotiating PPP contracts: reinforcing the 'P' in partnership. Transport Reviews, 35(2), 204-225.

https://doi.org/10.1080/01441647.2014.992495

Eldenburg, L. G., Gunny, K. A., Hee, K. W., \& Soderstrom, N. (2011). Earnings management using real activities: evidence from nonprofit hospitals. Accounting Review, 86(5), 16051630. https://doi.org/10.2308/accr-10095

Elwakil, E., \& Hegab, M. (2020). Investment possibility based models for public-private partnerships in water projects. $\mathrm{Ca}$ nadian Journal of Civil Engineering, 47(4), 461-469. https://doi.org/10.1139/cjce-2018-0361

Fama, E. F. (1980). Agency problems and the theory of the firm. Journal of Political Economy, 88(2), 288-307. https://doi.org/10.1086/260866

Fearnley, N., Bekken, J. T., \& Norheim, B. (2004). Optimal performance-based subsidies in Norwegian intercity rail transport. International Journal of Transport Management, 2(1), 29-38. https://doi.org/10.1016/j.ijtm.2004.04.003

Freixas, X., Guesnerie, R., \& Tirole, J. (1985). Planning under incomplete information and the ratchet effect. Review of Economic Studies, 52(2), 173-191.

https://doi.org/10.2307/2297615 
Fu, S. Z., Zhuo, H. M., Song, H., Wang, J. C., \& Ren, L. J. (2020). Examination of a coupling coordination relationship between urbanization and the eco-environment: a case study in Qingdao, China. Environmental Science and Pollution Research, 27(19), 23981-23993. https://doi.org/10.1007/s11356-020-08683-7

Geddes, R. R., \& Reeves, E. (2017). The favourability of US PPP enabling legislation and private investment in transportation infrastructure. Utilities Policy, 48, 157-165. https://doi.org/10.1016/j.jup.2017.07.002

Gibbons, R. (1992). Game theory for applied economists. Princeton University Press. https://doi.org/10.1515/9781400835881

Gill, D., \& Stone, R. (2010). Fairness and desert in tournaments. Games and Economic Behavior, 69(2), 346-364. https://doi.org/10.1016/j.geb.2010.01.002

Greco, L. (2015). Imperfect bundling in public-private partnerships. Journal of Public Economic Theory, 17(1), 136-146. https://doi.org/10.1111/jpet.12122

Guasch, J. L., Laffont, J.-J., \& Straub, S. (2006). Renegotiation of concession contracts: a theoretical approach. Review of Industrial Organization, 29(1-2), 55-73.

https://doi.org/10.1007/s11151-006-9109-5

Guetler, M., \& Guetler, O. (2014). The interaction of explicit and implicit contracts: a signaling approach. Journal of Economic Behavior \& Organization, 108, 135-146.

https://doi.org/10.1016/j.jebo.2014.09.006

Han, H., Wang, Z., \& Li, H. (2019). Incentive mechanism for inhibiting developer's moral hazard behavior in China's Sponge City projects. Advances in Civil Engineering, 2019, 6090683. https://doi.org/10.1155/2019/6090683

Hart, O. (2003). Incomplete contracts and public ownership: remarks, and an application to public-private partnerships. Economic Journal, 113(486), C69-C76.

Hart, O., \& Holmström, B. (1986). The theory of constracts. Cambridge University Press.

https://doi.org/10.1017/CCOL0521340446.003

Holmström, B. (1999). Managerial incentive problems: a dynamic perspective. The Review of Economic Studies, 66(1), 169-182. https://doi.org/10.1111/1467-937X.00083

Hu, Y., Wang, Y., Li, Y., \& Tong, X. (2018). An incentive mechanism in mobile crowdsourcing based on multi-attribute reverse auctions. Sensors, 18(10), 3453. https://doi.org/10.3390/s18103453

Hueskes, M., Verhoest, K., \& Block, T. (2017). Governing public-private partnerships for sustainability: an analysis of procurement and governance practices of PPP infrastructure projects. International Journal of Project Management, 35(6), 1184-1195. https://doi.org/10.1016/j.ijproman.2017.02.020

Jaramillo, J. J., \& Srikant, R. (2010). A game theory based reputation mechanism to incentivize cooperation in wireless ad hoc networks. Ad Hoc Networks, 8(4), 416-429.

https://doi.org/10.1016/j.adhoc.2009.10.002

Ke, Y., Wang, S. Q., \& Chan, A. P. C. (2009). Government incentives for private sector involvement in infrastructure PPP projects. Journal of Tsinghua University, 49(9), 1480-1483. https://doi.org/10.1201/9780203859926.ch123

Koo, J., Yoon, G.-S., Hwang, I., \& Barnerjee, S. G. (2013). A pitfall of private participation in infrastructure: a case of power service in developing countries. American Review of Public Administration, 43(6), 674-689. https://doi.org/10.1177/0275074012455453

Kreps, M. D., Milgrom, P., Roberts, J., \& Wilson, R. (1982). Rational cooperation in the finitely repeated prisoners' dilemma. Journal of Economic Theory, 27(2), 245-252. https://doi.org/10.1016/0022-0531(82)90029-1
Laffont, J. J., \& Tirole, J. (1988). The dynamics of incentive contracts. Econometrica, 56(5), 1153-1175. https://doi.org/10.2307/1911362

Lai, X. D., Wu, G. D., Shi, J. G., Wang, H. M., \& Kong, Q. S. (2015). Project value-adding optimization of project-based supply chain under dynamic reputation incentives. International Journal of Simulation Modelling, 14(1), 121-133. https://doi.org/10.2507/IJSIMM14(1)CO1

Li, H. M., Lv, L. L., Zuo, J., Bartsch, K., Wang, L. Y., \& Xia, Q. (2020a). Determinants of public satisfaction with an urban water environment treatment PPP project in Xuchang, China. Sustainable Cities and Society, 60, 102244. https://doi.org/10.1016/j.scs.2020.102244

Li, H. M., Lv, L. L., Zuo, J., Su, L. M., Wang, L. Y., \& Yuan, C. H. (2020b). Dynamic reputation incentive mechanism for urban water environment treatment PPP projects. Journal of Construction Engineering and Management, 146(8), 04020088. https://doi.org/10.1061/(ASCE)CO.1943-7862.0001879

Li, Y. F., Li, Y., Zhou, Y., Shi, Y. L., \& Zhu, X. D. (2012). Investigation of a coupling model of coordination between urbanization and the environment. Journal of Environmental Management, 98, 127-133. https://doi.org/10.1016/j.jenvman.2011.12.025

Li, S., Hu, D., Cai, J. N., \& Cai, H. B. (2020). Real option-based optimization for financial incentive allocation in infrastructure projects under public-private partnerships. Frontiers of Engineering Management, 7(3), 413-425. https://doi.org/10.1007/s42524-019-0045-0

Liu, J. C., Gao, R. L., Cheah, C. Y. J., \& Luo, J. (2016). Incentive mechanism for inhibiting investors' opportunistic behavior in PPP projects. International Journal of Project Management, 34(7), 1102-1111. https://doi.org/10.1016/j.ijproman.2016.05.013

Liu, Y., Sun, C. J. Y., Xia, B., Liu, S., \& Skitmore, M. (2018). Identification of risk factors affecting PPP waste-to-energy incineration projects in China: a multiple case study. Advances in Civil Engineering, 2018, 4983523. https://doi.org/10.1155/2018/4983523

Luo, B., Wang, C. Y., \& Li, C. Y. (2016). Incentive mechanism design aiming at deflated performance manipulation in retail firms: based on the ratchet effect and the reputation effect. Mathematical Problems in Engineering, 2016, 5412028. https://doi.org/10.1155/2016/5412028

Mohamed, I. S. (2015). Good governance, institutions and performance of public private partnerships. International Journal of Public Sector Management, 28(7), 566-582. https://doi.org/10.1108/IJPSM-01-2015-0005

Mohamed, K. A., Khoury, S. S., \& Hafez, S. M. (2011). Contractor's decision for bid profit reduction within opportunistic bidding behavior of claims recovery. International Journal of Project Management, 29(1), 93-107. https://doi.org/10.1016/j.ijproman.2009.12.003

Rablen, M. D. (2010). Performance targets, effort and risk-taking. Journal of Economic Psychology, 31(4), 687-697. https://doi.org/10.1016/j.joep.2010.05.002

Roychowdhury, S. (2006). Earnings management through real activities manipulation. Journal of Accounting \& Economics, 42(3), 335-370. https://doi.org/10.1016/j.jacceco.2006.01.002

Shang, L. M., \& Aziz, A. M. A. (2020). Stackelberg game theorybased optimization model for design of payment mechanism in performance-based PPPs. Journal of Construction Engineering and Management, 146(4), 04020029. https://doi.org/10.1061/(ASCE)CO.1943-7862.0001806 
Shi, L., Li, W. W., \& He, Y. J. (2020). An incentive analysis of availability payment mechanism in PPP projects. IEEE Access, 8 , 106046-106058. https://doi.org/10.1109/ACCESS.2020.2999932

Tadelis, S. (2016). The economics of reputation and feedback systems in e-commerce marketplaces. IEEE Internet Computing, 20(1), 12-19. https://doi.org/10.1109/MIC.2015.140

Peran, V. R. (2008). Subsidisation of urban public transport and the Mohring effect. Journal of Transport Economics and Policy, 42, 349-359.

van den Hurk, M., \& Verhoest, K. (2017). On the fast track? Using standard contracts in public-private partnerships for sports facilities: a case study. Sport Management Review, 20(2), 226-239. https://doi.org/10.1016/j.smr.2016.07.004

Villegas, J. E., Gonzalez, E. M., Gonzalez, M. P., Anguita, J. V., \& Vicent, J. L. (2005). Experimental ratchet effect in superconducting films with periodic arrays of asymmetric potentials. Physical Review B, 71(2), 024519. https://doi.org/10.1103/PhysRevB.71.024519

Wang, H., Xiong, W., Wu, G., \& Zhu, D. (2018). Public private partnership in public administration discipline: a literature review. Public Management Review, 20(2), 293-316. https://doi.org/10.1080/14719037.2017.1313445

$\mathrm{Xu}, \mathrm{F}$., \& Song, B. (2010). The dynamic incentive and monitor mechanism of government in public-private partnership projects. Chinese Journal of Management Science, 18(3), 165-173.

\section{Appendix 1}

(1) The proof of Equation (10)

According to incentive compatibility constraints $\left(\mathrm{IC}_{1}\right)$ and $\left(\mathrm{IC}_{2}\right)$, the private sector will select the optimal effort level in the second performance assessment cycle, to maximize the utility function of the performance. It can be realized by taking the first derivative of the effort level $\tilde{e}_{2}$ in the utility function $\tilde{\Phi}_{P 2}$ and setting it to 0 . Because

$$
\tilde{\Phi}_{P 2}=E\left(\begin{array}{l}
\gamma \tilde{A}\left(\pi_{2}\right)+(1-\gamma) \tilde{A}\left(\tilde{\pi}_{2}\right)-\frac{\gamma d}{2} \Delta \pi_{2}^{2}- \\
\frac{c}{2}\left(\tilde{e}_{2}^{2}+\theta_{2}^{2}\right)-\frac{\rho}{2} \sigma_{1}^{2}-(1-\gamma) \tilde{\beta}_{1} \Delta \pi_{1}
\end{array}\right),
$$

by taking the first derivative of $\tilde{e}_{2}$ and $\Delta \pi_{2}$ in the formula above and setting it to 0 , it can be obtained that:

$$
\begin{aligned}
& \frac{\partial \tilde{\Phi}_{P 2}}{\partial \tilde{e}_{2}}=\tilde{\beta}_{2} k \theta_{2}-c \tilde{e}_{2}=0, \\
& -(1-\gamma) \tilde{\beta}_{2}-\gamma d \Delta \pi_{2}=0 .
\end{aligned}
$$

By solving the formula above and according to $\Delta \pi_{2} \geq 0$, the optimal effort level and performance manipulation degree of the private sector in the second performance assessment cycle are obtained, respectively.

(2) The proof of Equations (11) and (12)

According to incentive compatibility constraints $\left(\mathrm{IC}_{3}\right)$ and $\left(\mathrm{IC}_{4}\right)$, the private sector who wants to select the optimal effort level in the first cycle needs to maximize the sum of its profit function in the two cycles. It can be obtained by taking the first derivative of the effort level $\tilde{e}_{1}$
Yi, X. (2016). Incentive mechanism of public-private partnership rail transit project from the perspective of multitask principal-agent model. Journal of Transporation Systems Engineering \& Information Technology, 16(3), 1-7.

Zhang, H., Jin, R., Li, H., \& Skibniewski, M. J. (2018). Pavement maintenance-focused decision analysis on concession periods of PPP highway projects. Journal of Management in Engineering, 34(1), 04017047.

https://doi.org/10.1061/(ASCE)ME.1943-5479.0000568

Zhang, H., \& Qiao, W. (2018). Research on the dynamic performance incentive mechanism incorporated with re-examination of PPP project. Journal of Zhejiang University. Sciences Edition, 45(2), 188-195.

Zhang, X. Q. (2005). Financial viability analysis and capital structure optimization in privatized public infrastructure projects. Journal of Construction Engineering and Management, 131(6), 656-668.

https://doi.org/10.1061/(ASCE)0733-9364(2005)131:6(656)

Zhang, Z., Wan, D., \& Jia, M. (2008). An empirical research on the relationship between partner's reputation and collaboration effects in PPP-accommodation function of formal contract and trust relationship. In Proceedings of 2008 International Conference on Public Administration (pp. 26-33), Minnesota, USA.

in the profit function $\tilde{\Phi}_{P 1}+\delta_{1} \tilde{\Phi}_{P 2}$ and setting it to 0 . Because

$$
\begin{aligned}
& \tilde{\Phi}_{P 1}+\delta_{1} \tilde{\Phi}_{P 2}=E\left(\begin{array}{l}
\gamma \tilde{A}\left(\pi_{1}\right)+(1-\gamma) \tilde{A}\left(\tilde{\pi}_{1}\right)- \\
\frac{\gamma d}{2} \Delta \pi_{1}^{2}-\frac{c}{2}\left(\tilde{e}_{1}^{2}+\theta_{1}^{2}\right)-\frac{\rho}{2} \sigma_{1}^{2}
\end{array}\right)= \\
& \delta_{1} E\left(\begin{array}{l}
\gamma \tilde{A}\left(\pi_{2}\right)+(1-\gamma) \tilde{A}\left(\pi_{2}\right)-\frac{\gamma d}{2} \Delta \pi_{2}^{2}- \\
\frac{c}{2}\left(\tilde{e}_{2}^{2}+\theta_{2}^{2}\right)-\frac{\rho}{2} \sigma_{2}^{2}+(1-\gamma) \tilde{\beta}_{1} \Delta \pi_{1}
\end{array}\right) .
\end{aligned}
$$

It is taken the first derivatives of the $\tilde{e}_{1}$ and $\Delta \pi_{1}$ in the formula above and setting them to 0 , respectively, that is

$$
\begin{aligned}
& \frac{\partial\left\{\tilde{\Phi}_{P 1}+\delta_{1} \tilde{\Phi}_{P 2}\right\}}{\partial \tilde{e}_{1}}=\tilde{\beta}_{1} k \theta_{1}-c \tilde{e}_{1}+\delta_{1} k \theta_{1} s \tau-\delta_{1} \tilde{\beta}_{2} l k \theta_{1}=0, \\
& \frac{\partial\left\{\tilde{\Phi}_{P 1}+\delta_{1} \tilde{\Phi}_{P 2}\right\}}{\partial \Delta \pi_{1}}=(1-\gamma)\left(\delta_{1} \tilde{\beta}_{2} l-\tilde{\beta}_{1}-\delta_{1} s \tau+\delta_{1} \tilde{\beta}_{1}\right)- \\
& \gamma d \Delta \pi_{1}=0 .
\end{aligned}
$$

Thus, the optimal effort level and performance manipulation degree of the private sector in the first cycle can be obtained.

(3) The proof of Equations (13) and (14)

According to the incentive mechanism model (Equation 9), on the basis of satisfying the participation constraint (IR) and incentive compatibility constraints $\left(\mathrm{IC}_{1}\right)--\left(\mathrm{IC}_{4}\right)$, the optimal incentive coefficients in the two performance assessment cycles should maximize the to- 
tal utility of the government (public sector) in the two cycles, namely $\max _{\tilde{\beta}_{1}, \tilde{\beta}_{2}}\left\{\tilde{\psi}_{G 1}+\delta_{1} \bar{\psi}_{G 2}\right\}$.

$$
\begin{aligned}
& \text { Because of } \\
& \tilde{\Psi}_{G 1}=E\left(\pi_{1}-\gamma \tilde{A}\left(\pi_{1}\right)-(1-\gamma) \tilde{A}\left(\tilde{\pi}_{1}\right)+\frac{\gamma d}{2} \Delta \pi_{1}^{2}-\frac{r}{2} h_{1}^{2}\right)
\end{aligned}
$$

and

$$
\tilde{\Psi}_{G 2}=E\left(\begin{array}{l}
\pi_{2}-\tilde{A}\left(\pi_{2}\right)-(1-\gamma) \tilde{A}\left(\tilde{\pi}_{2}\right)+ \\
\frac{\gamma d}{2} \Delta \pi_{2}^{2}-\frac{r}{2} h_{2}^{2}-(1-\gamma) \tilde{\beta}_{1} \Delta \pi_{1}
\end{array}\right),
$$

the following formulas are obtained:

$$
\tilde{\psi}_{G 1}=k \theta_{1} \tilde{\mathrm{e}}_{1}-a_{1}-\tilde{\beta}_{1} k \theta_{1} \tilde{\mathrm{e}}_{1}+\tilde{\beta}_{1} \Delta \pi_{1}-\tilde{\beta}_{1} \Delta \pi_{1} \gamma+\frac{\gamma d}{2} \Delta \pi_{1}^{2}-\frac{r}{2} h_{1}^{2}
$$

and

$$
\begin{aligned}
& \tilde{\Psi}_{G 2}=\left(1-\tilde{\beta}_{2}\right) k \theta_{2} \tilde{\mathrm{e}}_{2}-a_{1}-k \theta_{1} \tilde{\mathrm{e}}_{1} s \tau+(1-\gamma) s \tau \Delta \pi_{1}+ \\
& k \theta_{1} s \tau \hat{e}_{1}-\frac{r}{2} h_{2}^{2}+(1-\gamma) \tilde{\beta}_{2} \Delta \pi_{2}+\tilde{\beta}_{2} l k \theta_{1} \tilde{\mathrm{e}}_{1}+\frac{\gamma d}{2} \Delta \pi_{2}^{2}- \\
& (1-\gamma) \tilde{\beta}_{1} \Delta \pi_{1} .
\end{aligned}
$$

Therefore

$\tilde{\Psi}_{G 1}+\delta_{1} \bar{\psi}_{G 2}=\frac{\delta_{1} k^{2} \theta_{1}^{2} s \tau}{c}-\frac{\delta_{1} \tilde{\beta}_{2} l k^{2} \theta_{1}^{2}}{c}-$

$\frac{\tilde{\beta}_{1} k^{2} \theta_{1}^{2} \delta_{1} s \tau}{c}+\frac{\tilde{\beta}_{1} k^{2} \theta_{1}^{2} \delta_{1} \tilde{\beta}_{2} l}{c}-a_{1}-\frac{r}{2} h_{1}^{2}-\frac{r}{2} h_{2}^{2} \delta_{1}-$

$a_{1} \delta_{1}+\frac{(1-\gamma)^{2}\left(\delta_{1} \tilde{\beta}_{1}^{2}-\tilde{\beta}_{1}^{2}-\delta_{1} s \tau \tilde{\beta}_{1}+\delta_{1} \tilde{\beta}_{2} \tilde{\beta}_{1}\right)}{\gamma d}-$

$\frac{\tilde{\beta}_{2}^{2} k^{2} \theta_{2}^{2} \delta_{1}}{c}-\frac{\delta_{1}^{2} k^{2} \theta_{1}^{2} s^{2} \tau^{2}}{c}+\delta_{1} s \tau k \theta_{1} \hat{e}_{1}+$

$\frac{(1-\gamma)^{2}\left(\left(\delta_{1}-1\right) \tilde{\beta}_{1}-\delta_{1} s \tau+\delta_{1} l \tilde{\beta}_{2}\right)^{2}}{2 \gamma d}-$

$\frac{\tilde{\beta}_{1} k^{2} \theta_{1}^{2} \delta_{1} s \tau-\delta_{1}^{2} s \tau \tilde{\beta}_{2} l k^{2} \theta_{1}^{2}}{c}+\frac{\tilde{\beta}_{1} k^{2} \theta_{1}^{2} \delta_{1} \tilde{\beta}_{2} l}{c}-\frac{\tilde{\beta}_{2}^{2} l^{2} k^{2} \theta_{1}^{2} \delta_{1}^{2}}{c}+$

$\frac{\delta_{1}^{2} k^{2} \theta_{1}^{2} s \tau \tilde{\beta}_{2} l}{c}+\frac{(1-\gamma)^{2} \delta_{1} s \tau\left(\delta_{1} \tilde{\beta}_{1}-\tilde{\beta}_{1}-\delta_{1} s \tau+\delta_{1} l \tilde{\beta}_{2}\right)}{\gamma d}+$

$\frac{\tilde{\beta}_{2}^{2} k^{2} \theta_{2}^{2} \delta_{1}}{c} \frac{(1-\gamma)^{2} \delta_{1} \tilde{\beta}_{1}\left(\delta_{1} \tilde{\beta}_{1}-\tilde{\beta}_{1}-\delta_{1} s \tau+\delta_{1} \tilde{\beta}_{2}\right)}{\gamma d}$.

By taking the first derivative of the incentive coefficients $\tilde{\beta}_{1}$ and $\tilde{\beta}_{2}$ in the formula above and setting it to 0 , the results in Equations (13) and (14) are obtained. 